\title{
Molecular Insights into the Recognition of Acetylated Histone Modifications by the BRPF2 Bromodomain
}

\author{
Soumen Barman ${ }^{1}$, Anirban Roy ${ }^{1}$, Jyotirmayee Padhan, and Babu Sudhamalla, ${ }^{1, *}$ \\ ${ }^{1}$ Department of Biological Sciences, Indian Institute of Science Education and Research Kolkata, \\ Mohanpur Campus, Mohanpur, 741246 Nadia, West Bengal, India. \\ ${ }^{*}$ Correspondence: s.babu@iiserkol.ac.in
}

Short title: Recognition of acetylated histone by the BRPF2 bromodomain

Keywords: BRD, PTM, Histones, Acetyllysine, Mononucleosomes 


\begin{abstract}
HBO1 (HAT bound to ORC), a member of the MYST family of histone acetyltransferases (HATs), was initially identified as a binding partner of the origin recognition complex (ORC) that acetylates free histone $\mathrm{H} 3, \mathrm{H} 4$, and nucleosomal H3. It functions as a quaternary complex with the BRPF (BRPF1/2/3) scaffolding protein and two accessory proteins, ING4/5 and Eaf6. BRPF2 interaction with $\mathrm{HBO} 1$ has been shown to be important for regulating $\mathrm{H} 3 \mathrm{~K} 14$ acetylation during embryonic development. However, how the BRPF2 directs the HBO1 HAT complex to chromatin to regulate its HAT activity towards nucleosomal substrates remains unclear. Our findings reveal novel interacting partners of the BRPF2 bromodomain that recognizes different acetyllysine residues on the N-terminus of histone $\mathrm{H} 4, \mathrm{H} 3$, and $\mathrm{H} 2 \mathrm{~A}$ and preferentially binds to $\mathrm{H} 4 \mathrm{~K} 5 \mathrm{ac}$, H4K8ac, and H4K5acK12ac modifications. Moreover, pull-down assays on the endogenous histones and mononucleosomes isolated from human cells confirmed that the BRPF2 bromodomain specifically showed a stronger affinity to H4K5ac marks. Further, mutational analysis of BRPF2 bromodomain coupled with ITC binding and pull-down assays on the histone substrates identified critical residues responsible for acetyllysine binding. Together, our study provides novel insights into how the histone binding function of the BRPF2 bromodomain directs the recruitment of the HBO1 HAT complex to chromatin to regulate gene expression.
\end{abstract}




\section{INTRODUCTION}

Histones are the basic proteins that package the DNA and are often subjected to a variety of posttranslational modifications (PTMs), such as acetylation, methylation, phosphorylation, and ubiquitylation. ${ }^{1-3}$ These PTMs are reversible, and they are dynamically regulated by a specialized class of proteins called 'writers' and 'erasers', which enzymatically add and remove the PTM marks, respectively. ${ }^{4}$ Different patterns of PTMs, which recruit the effector proteins to the chromatin, acts as an 'off-on switch' to regulate gene expression. ${ }^{5}$ Histone PTMs are recognized by another class of proteins called 'readers'; these proteins bind to the specific PTM with the help of specialized domains and act as a scaffold for the recruitment of other regulatory complexes for downstream transcriptional regulation. ${ }^{6}$

Initially discovered 50 years ago, as a unique modification in histones, lysine acetylation is currently the most widely studied histone PTM. ${ }^{5}$ Acetylation marks are now known to also occur on thousands of nonhistone proteins in virtually every cellular compartment. ${ }^{7-9}$ This modification is recognized by specialized reader modules called bromodomains, which share a conserved globular fold and are composed of a left-handed bundle of four $\alpha$-helices $\alpha \mathrm{Z}, \alpha \mathrm{A}, \alpha \mathrm{B}$, and $\alpha \mathrm{C} .{ }^{10}$ The helices are linked by two loop regions (ZA and BC), which form the hydrophobic acetyllysine $(\mathrm{Kac})$ binding pocket. ${ }^{10}$ Moreover, the bromodomain and the acetyllysine binding is stabilized by hydrogen bonds with water molecules and a conserved asparagine 'anchor' residue in the bromodomain. Sixty-one different bromodomains have been identified so far, which recognize multiple acetylated lysine residues on the N-terminus of the histone tail. ${ }^{10,11}$ Although the acetyllysine recognition occurs in the conserved structural fold of the bromodomain, selectivity is achieved through variation in the ZA and BC loop regions. ${ }^{10}$ 
The bromodomain and PHD finger (BRPF) family proteins are a sub-class of the bromodomain family and include BRPF1, BRPF2, and BRPF3. ${ }^{10,11}$ These proteins contain an Nterminal PZP domain (two PHD fingers connected through a zinc knuckle), a bromodomain, and a C-terminal PWWP (Pro-Trp-Trp-Pro) domain (Figure 1A). ${ }^{12,13}$ BRPFs are chromatin binding scaffolding proteins and are components of the histone acetyltransferases (HATs) complexes. ${ }^{13}$ For example, BRPF1 forms a tetrameric complex with MOZ/MORF HAT, which acetylates several lysine residues on histone $\mathrm{H} 3$ and H4. ${ }^{14-17}$ Alternatively, BRPF2/3 associates with HBO1 HAT (Figure 1B), which acetylates K5, K8, and K12 of histone H4 and H3 at K14. ${ }^{18-21}$ BRPF family proteins stimulate and modulate the enzymatic activity of HATs and promote acetylation of histone lysine residues during transcription. ${ }^{22-24}$

The association of BRPFs with HATs plays a crucial role in development and disease progression. For example, the BRPF1-MOZ complex is essential for $H O X$ gene expression in vertebrate segmentation and patterning. ${ }^{25}$ In both zebrafish and medaka fish models, BRPF1 mutation decreases $H O X$ gene expression, which impairs proper skeletal development. ${ }^{25,} 26$ Similarly, the BRPF2-HBO1 complex regulates transcriptional activation of genes involved in the differentiation of erythrocytes in mice. ${ }^{21}$ Furthermore, BRPF2 deficient embryos develop severe anemia and do not survive due to impaired fetal liver erythropoiesis. ${ }^{21}$ The BRPF family proteins are also involved in bone degradation, and pharmacological inhibition of their bromodomain prevented osteoclastogenesis in murine and human cells. ${ }^{27}$ Apart from their role in development, BRPFs are misregulated in many diseases, including cancer. BRPF1 is among the most significantly upregulated gene in hepatocellular carcinoma. ${ }^{28}$ It increases the expression of critical oncogenes like $E 2 F 2$ and $E Z H 2$ by facilitating their promoter acetylation in H3K14 through MOZ/MORF complex. ${ }^{28}$ BRPFs are increasingly becoming an attractive therapeutic 
target in cancer and various other diseases, attributed to their role in transcription and cell cycle. ${ }^{28}$ Potent and selective inhibitors for the BRPF family bromodomains have been developed in recent studies. For example, PFI-4 is highly selective for the BRPF1B isoform, BAY-299 is a potent and selective inhibitor for the BRPF2 bromodomain, and (OF-1, NI-57) have been reported as panBRPF bromodomain inhibitors. ${ }^{29,} 30$

The BRPF proteins recruit to chromatin by coordinating with their various domains that interact with histone and DNA. ${ }^{24,31}$ The PZP domain binds unmethylated histone H3K4 while PWWP recognizes the H3K36me3 mark and the bromodomains of the BRPF family have a high affinity for multiple acetylated histone marks. ${ }^{31-33}$ Recent studies on the BRPF1 bromodomain revealed that it recognizes multiple acetyllysine residues on the histone $\mathrm{H} 2 \mathrm{~A}, \mathrm{H} 3$, and $\mathrm{H} 4$ and preferentially binds to diacetylated histone H4K5acK8ac and H4K5acK12ac ligands. ${ }^{34,} 35$ Similarly, the BRPF3 bromodomain has a strong affinity for histone ligands such as H4K5ac and H4K5acK12ac. ${ }^{36}$ Although, it is reported that the BRPF2 bromodomain binds weakly to diacetylated (H4K5acK8ac) and dipropionylated (H4K5prK8pr) histone ligands, ${ }^{37}$ there is still limited histone ligand information available for the BRPF2 bromodomain (Figure 1C). We sought to identify novel acetylated histone ligands recognized by the BRPF2 bromodomain through a series of computational, biophysical, and biochemical methods. We report that the BRPF2 bromodomain binds to multiple acetyllysine residues on the N-terminal tails of histone $\mathrm{H} 4$, $\mathrm{H} 3$, and H2A. Moreover, we have characterized the mode of acetyllysine binding in the hydrophobic binding pocket of the BRPF2 bromodomain.

\section{MATERIALS AND METHODS}


Peptide Synthesis. All histone peptides were synthesized by (GL Biochem Ltd., and S. Biochem Ltd.) and purified by HPLC to $98 \%$ purity. The integrity of the purified peptides were confirmed by LC-ESI mass spectrometry. Peptide concentrations were determined based on the observation that $1 \mathrm{mg} / \mathrm{ml}$ peptide generates an absorbance value $\left(\mathrm{A}_{205}\right)$ of 30 at $205 \mathrm{~nm}$.

Expression and Purification of BRPF2 Bromodomain. The N-terminal His 6 -tagged wild-type BRPF2 bromodomain plasmid (a gift from Nicola-Burgess-Brown, addgene ID: 39095) was transformed into One Shot BL21 star (DE3) E. coli competent cells (Invitrogen cat\#C601003) using pNIC28-Bsa4 kanamycin-resistant vectors. A single colony was picked up and grown overnight at $37^{\circ} \mathrm{C}$ in $10 \mathrm{~mL}$ of Luria-Bertani (LB) broth in the presence of $50 \mu \mathrm{g} \mathrm{mL}{ }^{-1}$ kanamycin. The culture was diluted 100 -fold and allowed to grow at $37^{\circ} \mathrm{C}$ to an optical density $\left(\mathrm{OD}_{600}\right)$ of 1.0. Protein expression was induced overnight at $17^{\circ} \mathrm{C}$ with $0.5 \mathrm{mM}$ IPTG in an Innova 44 Incubator shaker (New Brunswick Scientific). Proteins were purified as follows: Harvested cells were resuspended in $15 \mathrm{~mL}$ lysis buffer (50 mM HEPES pH 7.5, $300 \mathrm{mM} \mathrm{NaCl}, 5 \mathrm{mM} \beta$ mercaptoethanol, 5\% glycerol, $25 \mathrm{mM}$ imidazole, Lysozyme, DNase, and 1:200 (v/v) Protease Inhibitor Cocktail III (Calbiochem). The cells were lysed by pulsed sonication and centrifuged at $13000 \mathrm{rpm}$ for $40 \mathrm{~min}$ at $4^{\circ} \mathrm{C}$. According to the manufacturer's instructions, the soluble extracts were subject to Ni-NTA agarose resin (QIAGEN cat\#30210). After passing 20 volumes of washing buffer (50 mM HEPES pH 7.5, 300 mM NaCl, 5 mM $\beta$-mercaptoethanol, 5\% glycerol, and $25 \mathrm{mM}$ imidazole), proteins were eluted with a buffer containing $50 \mathrm{mM}$ HEPES pH 7.5, 300 $\mathrm{mM} \mathrm{NaCl}, 5 \mathrm{mM} \beta$-mercaptoethanol, 5\% glycerol, and $250 \mathrm{mM}$ imidazole. Proteins were further purified by gel filtration chromatography (Superdex-75) using AKTA pure FPLC system (GE Healthcare) with a buffer containing $50 \mathrm{mM}$ HEPES pH 7.5, $200 \mathrm{mM} \mathrm{NaCl}$, and 5\% glycerol. 
Purified proteins were concentrated using Amicon Ultra-10k centrifugal filter device (Merck Millipore Ltd.), and the concentration was determined using Bradford assay kit (Bio-Rad Laboratories) with BSA as a standard. The proteins were aliquoted and stored at $-80^{\circ} \mathrm{C}$ before use.

Isothermal Titration Calorimetry Measurements. Isothermal titration calorimetry (ITC) was carried out on a MicroCal PEAQ-ITC instrument (Malvern). Experiments were conducted at $15^{\circ} \mathrm{C}$ while stirring at $750 \mathrm{rpm}$. Buffers of protein and peptides were matched to $50 \mathrm{mM}$ HEPES, $\mathrm{pH}$ 7.5, $200 \mathrm{mM} \mathrm{NaCl}$, and 5\% glycerol. Each titration comprised one initial injection of $0.4 \mu \mathrm{L}$ lasting $0.8 \mathrm{~s}$, followed by 18 injections of $2 \mu \mathrm{L}$ lasting $4 \mathrm{~s}$ each at $2.5 \mathrm{~min}$ intervals. The initial injection was discarded during data analysis. The microsyringe ( $40 \mu \mathrm{L})$ was loaded with a peptide sample solution, and the peptide concentration varied from $0.3 \mathrm{mM}$ to $1 \mathrm{mM}$. It was injected into the cell $(200 \mu \mathrm{L})$, occupied by a protein concentration of $100 \mu \mathrm{M}$. All the data was fitted to a single binding site model using the MicroCal PEAQ-ITC analysis software to calculate the stoichiometry $(\mathrm{N})$, the binding constant $\left(\mathrm{K}_{\mathrm{D}}\right)$, enthalpy $(\Delta \mathrm{H})$, and entropy $(\Delta \mathrm{S})$ of the interaction. The final titration figures were prepared using OriginPro 2020 software (OriginLab).

Protein-Peptide Docking. The crystal structure of the BRPF2 bromodomain (PDB: 3RCW) was used for molecular docking studies, and the polar hydrogen atoms were added using PyMoL software. The histone H4 coordinates were retrieved from the RCSB protein data bank, and the selected lysine residues were covalently modified using the PyTM plugin of PyMoL (version 1.8.4.0) software. The protein and histone peptide input structures were prepared, such as adding charges, assigning the atom types, and detecting the root for the ligand molecules were done by 
using the AutoDock tools. The grid box dimensions were set to $60 \mathrm{X} 58 \mathrm{X} 65 \AA$ along the $X, Y$, and $Z$ axes with a default grid spacing of $1 \AA$, which covered the entire protein. Molecular docking of each modified histone peptide with BRPF2 bromodomain was performed using AutoDockVina 1.1.2. ${ }^{38}$ Molecular interaction between each peptide and bromodomain was analyzed using PyMOL (version 2.3.4) software package.

Molecular Dynamics. The best-ranked docked conformations of BRPF2 bromodomain and acetylated histone $\mathrm{H} 4$ peptides were subjected to $150 \mathrm{~ns}$ of MD simulations with GROMACS (version 2018.3) software package using the CHARMM27 all atom force field. ${ }^{39,}{ }^{40}$ In order to set up the MD simulations for the protein-peptide complexes, the topology parameters of BRPF2 bromodomain and acetylated histone H4 peptides were created using GROMACS. The prepared protein-peptide complexes were then solvated in a dodecahedron box with a distance of $1.0 \mathrm{~nm}$ between the complex and edge of the solvated box. The solvated system was neutralized by adding sodium and chloride ions in the simulation. To ensure the complex's steric clashes or geometry, the system was energy minimized using the LINCS constraints and steepest descent algorithms followed by system equilibration under NVT and NPT ensembles. Final MD simulations of bromodomain and peptide complexes were carried out at $300 \mathrm{~K}$ temperature, 1 atm pressure and $2 \mathrm{fs}$ time step for $150 \mathrm{~ns}$. The final MD trajectories were analyzed to calculate the RMSD (root mean square deviation), RMSF (root mean square fluctuation) and Rg (radius of gyration) values by using the standard GROMACS functions.

Mammalian Cell Culture. HeLa cells were grown in DMEM supplemented with 10\% fetal bovine serum and antibiotics (Penicillin-Streptomycin cocktail) in a humidified atmosphere 
containing $5 \% \mathrm{CO}_{2}$. Cells at $\sim 90 \%$ confluence stage were treated with $2 \mu \mathrm{M}$ of histone deacetylase inhibitor Trichostatin A (TSA, cat\# T8552, Sigma) dissolved in DMSO to generate hyperacetylated histones. Twenty hours post-treatment, media was removed and rinsed the cells with cold PBS buffer. The harvested cells were rewashed with cold PBS buffer and frozen as a dry pellet at $-80^{\circ} \mathrm{C}$.

Acid Extraction of Histones. Histones were extracted from HeLa cells using the acid-extraction protocol as previously described. ${ }^{41}$ Briefly, frozen cell pellets from $100 \mathrm{~mm}$ dish of HeLa cells were resuspended in $1 \mathrm{ml}$ of hypotonic lysis buffer $(10 \mathrm{mM}$ Tris- $\mathrm{HCl} \mathrm{pH} 8.0,1 \mathrm{mM} \mathrm{KCl}, 1.5 \mathrm{mM}$ $\mathrm{MgCl}_{2}, 1 \mathrm{mM}$ DTT, $1 \mathrm{mM}$ PMSF, and protease inhibitor cocktail) and incubated for $30 \mathrm{~min}$ on rotator at $4^{\circ} \mathrm{C}$. Samples were then centrifuged $\left(10,000 \times \mathrm{g}, 10 \mathrm{~min}\right.$ at $\left.4^{\circ} \mathrm{C}\right)$, and the supernatant was discarded entirely. The nuclei resuspended in $800 \mu \mathrm{L}$ of $0.4 \mathrm{~N} \mathrm{H}_{2} \mathrm{SO}_{4}$, vortexed intermittently for $5 \mathrm{~min}$, and further incubated at $4^{\circ} \mathrm{C}$ on a nutator for overnight. The nuclear debris was pelleted by centrifugation $\left(16000 \times \mathrm{g}, 10 \mathrm{~min}\right.$ at $\left.4^{\circ} \mathrm{C}\right)$, and the supernatant containing histones were collected. The histones were precipitated by adding $264 \mu \mathrm{L}$ TCA (Trichloroacetic acid) drop by drop to histone solution and invert the tube several times to mix the solutions and incubated the samples on ice for $30 \mathrm{~min}$. Finally, histones were pelleted by centrifugation $(16000 \mathrm{x} \mathrm{g}, 10 \mathrm{~min}$ at $4^{\circ} \mathrm{C}$ ), and the supernatant was discarded. The histones pellet was washed twice with ice-cold acetone, followed by centrifugation $\left(16000 \times \mathrm{g}, 5 \mathrm{~min}\right.$ at $\left.4^{\circ} \mathrm{C}\right)$, and carefully removed the supernatant. The histone pellet was air-dried for $20 \mathrm{~min}$ at room temperature and subsequently dissolved in an appropriate volume of $\mathrm{ddH} 2 \mathrm{O}$ and transferred into a fresh tube. The aliquoted histones were stored at $-80^{\circ} \mathrm{C}$ before use. 
Isolation of Mononucleosomes From HeLa Cells. Nucleosomes were isolated from HeLa cells by following the protocol as previously described. ${ }^{42,}{ }^{43}$ Briefly, the cells were harvested after twenty hours of post-treatment with $2 \mu \mathrm{M}$ histone deacetylase inhibitor (TSA) and washed twice in PBS buffer. The cells were resuspended in buffer A (10 mM HEPES pH 7.9, $10 \mathrm{mM} \mathrm{KCl,} 1.5$ $\mathrm{mM} \mathrm{MgCl} 2,340 \mathrm{mM}$ sucrose, $10 \%$ (v/v) glycerol, protease inhibitor cocktail (Pierce), $1 \mu \mathrm{g} / \mathrm{mL}$ TSA, $5 \mathrm{mM}$ 2-mercaptoethanol), and an equivalent volume of buffer A supplemented to $0.1 \%$ (v/v) Triton X-100 detergent and incubated on ice for $10 \mathrm{~min}$. The nuclei were pelleted by centrifugation $\left(1300 \mathrm{xg}\right.$, for $5 \mathrm{~min}$, at $4^{\circ} \mathrm{C}$ ) and washed twice with ice-cold buffer $\mathrm{A}$, followed by centrifugation $\left(1300 \mathrm{x} \mathrm{g}, 5 \mathrm{~min}\right.$ at $\left.4^{\circ} \mathrm{C}\right)$ and carefully removed the supernatant. The nuclei were resuspended in buffer $\mathrm{A}$, and the concentration of nucleic acid was measured by following the protocol previously described, ${ }^{44}$ and then $\mathrm{CaCl}_{2}$ was added to $2 \mathrm{mM}$. The nuclei suspension was preincubated at $37^{\circ} \mathrm{C}$ for $5 \mathrm{~min}$ and followed by micrococcal nuclease (Worthington, cat\# LS004798); digestion was carried out by following the manufacturer's protocol. To facilitate the release of digested nucleosomes, $\mathrm{NaCl}$ was added to final concentrations of $200 \mathrm{mM}$, and reactions spun down at $1300 \mathrm{x}$ for $5 \mathrm{~min}$ at $4^{\circ} \mathrm{C}$. The supernatant containing soluble nucleosomes were collected and stored at $-80^{\circ} \mathrm{C}$ before use.

Ni-NTA Pull-down Assays and Western Blotting. 15-20 $\mu \mathrm{g}$ of acid extracted histones or nucleosomes isolated from HeLa cells were mixed with $50 \mu \mathrm{M}$ of recombinant His 6 -taggedBRPF2 bromodomain incubated at $4^{\circ} \mathrm{C}$ on a nutator for $60 \mathrm{~min}$ in the presence or absence of 10 $\mu$ M BAY-299 (abcam cat\# ab230368) inhibitor. Samples were transferred to a fresh tube containing $50 \mu \mathrm{l}$ of Ni-NTA agarose (QIAGEN) and incubated for $60 \mathrm{~min}$ at $4^{\circ} \mathrm{C}$ on a nutator. The beads were then washed five times with $1 \mathrm{ml}$ of wash buffer containing $50 \mathrm{mM}$ HEPES pH 
7.5, $500 \mathrm{mM} \mathrm{KCl,} 2 \mathrm{mM}$ EDTA, 0.1\% NP-40. Bound histones or nucleosomes were eluted by incubating the beads in $20 \mu \mathrm{l}$ of elution buffer (50 mM HEPES pH 7.5 and $500 \mathrm{mM}$ Imidazole) at $4^{\circ} \mathrm{C}$ on a nutator. Equal volumes of eluted samples were separated on a $12 \%$-SDS-PAGE gel and transferred onto a $0.45 \mu \mathrm{m}$ PVDF membrane at a constant voltage of $80 \mathrm{~V}$ for an hour at $4^{\circ} \mathrm{C}$. The membrane was rinsed in TBST buffer (50 mM Tris $\mathrm{pH} 7.4,200 \mathrm{mM} \mathrm{NaCl}$, and 0.1\% Tween20) and blocked for an hour at room temperature (RT) in 5\% milk buffer prepared in TBST. Immunoblotting was performed with the following primary antibodies: H4K5ac (Invitrogen cat\# MA532009), H4K8ac (Invitrogen cat\# MA533386), H4K12ac (Invitrogen cat\# MA533388), and H4K16ac (Invitrogen cat\# MA527794) overnight at $4^{\circ} \mathrm{C}$. The membranes were washed with TBST buffer thrice at RT for five minutes each. The blots were then incubated with the HRP conjugated secondary antibodies Goat anti-Rabbit IgG (Invitrogen cat\# 31466) or Goat antimouse IgG (Invitrogen cat\# 31431) with 5\% nonfat dry milk, dilution 1:20000 in TBST. The membranes were rewashed with TBST buffer thrice at RT for five minutes each. Protein bands were visualized by chemiluminescence using SuperSignal West Femto substrate (Invitrogen cat\# 34094) following the manufacturer's protocol.

Circular Dichroism Spectroscopy. Circular Dichroism (CD) spectra were recorded on a JASCO J-1500 CD Spectrometer (JASCO, Japan) at $20^{\circ} \mathrm{C}$ using a quartz cell with a path length of $10 \mathrm{~mm}$. Two scans were accumulated at a scan speed of $100 \mathrm{~nm} \mathrm{~min}^{-1}$, with data being collected at every $\mathrm{nm}$ from 195 to $260 \mathrm{~nm}$. The BRPF2 wild-type and its mutant proteins were diluted to $2-5 \mu \mathrm{M}$ concentartion in $\mathrm{CD}$ buffer containing $150 \mathrm{mM} \mathrm{NaCl}$ and $50 \mathrm{mM} \mathrm{NaH} \mathrm{PO}_{4}$ at $\mathrm{pH}$ 7.0. The ellipticity data was converted into molar ellipticity using the below equation.

$$
[\Theta]=\mathrm{m}^{0 *} \mathrm{M} /(10 * \mathrm{~L} * \mathrm{C})
$$


Where $[\Theta]$ is the molar ellipticity, $\mathrm{m}^{\circ}$ is ellipticity of the sample measured, $\mathrm{M}$ is average molecular weight $(\mathrm{g} / \mathrm{mol}), \mathrm{L}$ is path length of the cell $(\mathrm{cm})$, and $\mathrm{C}$ is a concentration in $\mathrm{g} / \mathrm{L}$. The protein secondary structure determination was done using K2D3 structure prediction software. ${ }^{45}$

Thermal Shift Assay. The thermal shift assay is a rapid and inexpensive biochemical method often used to determine the thermal stability of protein in different in vitro conditions by monitoring the unfolding of the protein at increasing temperatures. The SYPRO orange fluorescent dye (Invitrogen, cat\# S6650) was used to calculate the melting temperature $\left(T_{\mathrm{m}}\right)$ of the wild-type BRPF2 bromodomain and its mutant proteins. The assay was performed in a 96-well clear lowprofile plate (Bio-Rad, \#MLL9601) using CFX96 touch Real-Time PCR detection system. A total $25 \mu \mathrm{L}$ assay containing $10 \mu \mathrm{g}$ BRPF2 and its mutants were premixed with 5x SYPRO orange dye in $50 \mathrm{mM}$ HEPES, pH7.5, $200 \mathrm{mM} \mathrm{NaCl}$, and 5\% glycerol. Wells containing only buffer with 5x dye were used for baseline correction. The plate was sealed with an optically clear adhesive film (Bio-Rad, \#MSB1001) to prevent sample loss during heating. The temperature was gradually ramped up from 25 to $95{ }^{\circ} \mathrm{C}$ while monitoring the change in fluorescence intensity of the dye. GraphPad Prism software was used to analyze the data and calculate the melting point of the protein sample by applying nonlinear regression using the melting Boltzmann equation:

$$
Y=\text { bottom }+(\text { top }- \text { bottom } /(1+\exp (T m-X / \text { slope }))
$$

\section{RESULTS}

The BRPF2 Bromodomain Recognizes Multiple Acetyllysine Marks on N-terminal Histone

Tails. The bromodomains of BRPF2 and BRPF3 share high sequence similarity and function as part of the HBO1 HAT complex, but there is limited information on which histone ligands they 
bind. We recently identified multiple acetylated histone ligands recognized by the BRPF3 bromodomain using high-throughput virtual screening and in-vitro methods. ${ }^{36}$ Considering the high sequence similarity between the bromodomains of BRPF2 and BRPF3, they are likely to recognize a similar subset of acetylated histone modifications. To investigate the function of the BRPF2 bromodomain, we recombinantly overexpressed the protein in E.coli cells and purified it with high homogeneity (Figure S1). We performed ITC binding assays using various combinations of mono-, di- and multiple-acetylated synthesized peptides covering histone H4, H3, and H2A (Figure 1D). We found that the BRPF2 bromodomain interacts strongly with the histone H4K5ac (1-10), H4K5acK12ac (1-15), and H4K8ac (1-15) (Figure 2, Figure 3A, and Table 1), moderately with H4Kac4 (H4K5/8/12/16) (1-20) ligand (Figure 3D and Table 1), but weakly with H4K12ac (1-20), H4K16ac (11-21), H3K14ac (9-19), and H2AK5ac (1-12) ligands (Figure 3B,C and 3E,F, and Table 1).

Our ITC binding results demonstrate that the BRPF2 bromodomain preferentially binds to the histone H4K5ac (1-10), H4K8ac (1-15), and H4K5acK12ac (1-15) peptides with the strongest affinities $\left(K_{\mathrm{D}}=1.4 \pm 0.02 \mu \mathrm{M}, 5.2 \pm 0.7 \mu \mathrm{M}\right.$, and $\left.1.2 \pm 0.01 \mu \mathrm{M}\right)$ respectively (Figure 2A,B, Figure $3 \mathrm{~A}$ and Table 1). The combination of H4K5acK12ac marks increased the BRPF2 bromodomain binding affinity about forty-fold over that of the mono-acetylated H4K12ac mark $\left(K_{\mathrm{D}}=1.4 \pm 0.02 \mu \mathrm{M}\right.$ versus $\left.55.2 \pm 4.0 \mu \mathrm{M}\right)$, and also has a similar affinity compared to the H4K5ac modification (Figure 2B and Table 1). Weak interaction was observed for the monoacetylated H4K16ac (11-21) ligand (Figure 3C). Next, we tested tetra-acetylated H4Kac4 peptide carrying the acetylation sites at K5/8/12/16 on N-terminal tails of histone $\mathrm{H} 4$. We found that the BRPF2 bromodomain bound to H4Kac4 (1-20) peptide with a dissociation constant of $\left(K_{\mathrm{D}}=20.5\right.$ $\pm 2.0 \mu \mathrm{M}$ ), which is about 2.5 fold stronger than the H4K12ac (1-20) peptide (Figure 3B,D and 
Table 1). These results suggest that the BRPF2 bromodomain recognizes multiple acetylation marks on histone $\mathrm{H} 4$, with $\mathrm{K} 5 \mathrm{ac}$ recognition driving the binding interaction, and the combination of K12ac did not affect the binding, while the inclusion of K8ac and K16ac could be inhibitory.

More recent studies on the family IV bromodomains revealed that BRPF1 recognizes H3K14ac and H2AK5ac ligands with a moderate affinity, and the BRPF3 and ATAD2/B forms transient interactions with the histone H2AK5ac ligand. ${ }^{34-36,46,47} \mathrm{We}$ also tested the binding affinity of the BRPF2 bromodomain with histone peptides H3K14ac (9-19) and H2AK5ac (1-12). We found that the BRPF2 bromodomain binds to H3K14ac and H2AK5ac peptides with dissociation constants $\left(K_{\mathrm{D}}=200.2 \pm 20 \mu \mathrm{M}\right.$ and $\left.165.2 \pm 15 \mu \mathrm{M}\right)$ respectively (Figure 3E,F, Table 1). No binding was observed in the case of unmodified histone H4 (1-20), H3 (1-24), and H2A (1-12) peptides (Figure S2A-C). Collectively, our ITC binding results demonstrate that the BRPF2 bromodomain strongly recognizes multiple acetyllysine residues on the N-terminal tails of histone H4.

MD Simulations Predict the Acetyllysine Binding Pocket Residues. We carried out molecular dynamics (MD) simulations to understand the mode of acetyllysine binding and stability of the bromodomain-histone peptide complexes. Fitst, we covalently modified the selected lysine residues on the $\mathrm{N}$-terminal tails of histone $\mathrm{H} 4$ using an in-silico approach. Next, we carried out flexible docking studies for the BRPF2 bromodomain with unacetylated and acetylated histone H4 (H4K5ac and H4K5acK12ac) ligands. The best ranked binding conformations of histone ligands obtained from docking studies were used to perform the MD simulations. The RMSD (Root mean square deviation) was used to analyze the stability of the bromodomain and histone peptide complexes. RMSD results revealed that both acetylated ligands H4K5ac and 
H4K5acK12ac are stable throughout the simulations, whereas unacetylated $\mathrm{H} 4$ ligand has significantly deviated within 100 ns of MD simulation (Figure 4A). Similarly, the analysis of RMSF (Root mean square fluctuation) for each residue demonstrates that unacetylated H4 ligand showed significant fluctuations in the ZA loop of the bromodomain compared to the acetylated H4 ligands (Figure 4B). These results highlight the importance of the ZA loop in acetyllysine recognition and stabilizing the interactions between the bromodomain and acetylated histone peptide complexes.

Next, the visual analysis of MD trajectories revealed that the K5ac residue in two of the histone peptides, H4K5ac and H4K5acK12ac inserts deep into the binding cavity of the BRPF2 bromodomain (Figure 5A,B). Further, the analysis of MD trajectories using the PLIP (ProteinLigand Interaction Profiler) server (30) demonstrates that coordination of the K5ac residue of H4K5ac and H4K5acK12ac peptides occurs through a combination of hydrogen bonds and hydrophobic interactions with the bromodomain binding pocket residues (Figure 5C,D). Specifically, the K5ac residue of the H4K5ac peptide forms a hydrogen bond interaction with the critical acetyllysine binding pocket residue Y599 of the bromodomain. Similarly, the K5ac residue of the H4K5acK12ac peptide interacts with two critical binding pocket residues, Y599 and N642 of the BRPF2 bromodomain, through hydrogen bonding (Figure 5C,D and Table 2). In addition, the K5ac residue of both the $\mathrm{H} 4$ peptides makes hydrophobic interactions with 'RIF' shelf residues I586 and F587, and F648 of the BC loop region of the bromodomain. Together, these results correspond to the ITC binding studies conducted with the multiple acetylated histone H4 peptides, and the K5ac recognition mainly drives the binding interaction with the BRPF2 bromodomain. 
BRPF2 Bromodomain Recognizes Endogenous Acetylated Histone H4. To address whether the BRPF2 bromodomain binds to endogenous acetylated histone H4, we performed pull-down assays by incubating the recombinantly produced 6xHis-tagged BRPF2 bromodomain with hyperacetylated H4 isolated from human cells (Figure 6A and Figure S3). Subsequent enrichment with Ni-NTA beads and probing of the bound material by western blot against anti-H4ac antibodies revealed that the BRPF2 bromodomain efficiently binds to endogenous histone H4K5ac and H4K8ac as compared to H4K12ac and H4K16ac marks (Figure 6B). Notably, the BRPF2 inhibitor BAY-299 reduced the interaction approximately 3-fold between the BRPF2 bromodomain and acetylated histone $\mathrm{H} 4$, as probed with anti-H4K5ac antibody. (Figure 6C). We carried out computational molecular docking studies to further investigate the mode of inhibitor binding in the bromodomain binding pocket. Our docking results revealed that BAY-299 preferably occupies the acetyllysine binding pocket of the BRPF2 bromodomain and forms a hydrogen bond with the anchor (N642) residue (Figure 6D), which is a highly conserved residue throughout the bromodomain family and critical for acetyllysine recognition. ${ }^{10}$ Unfortunately, no antibodies are currently available that specifically recognize diacetyllysine marks on histone $\mathrm{H} 4$. Together, these results demonstrate that the BRPF2 bromodomain can recognize the identified histone H4 marks at the endogenous histone level.

\section{Mutational Analysis Identifies Bromodomain Binding Pocket Residues that are Critical for}

Acetyllysine Recognition. Next, we sought to investigate the amino acid residues important for bromodomain-acetyllysine recognition. With the help of our MD simulation studies, we specifically targeted five amino acid residues for the mutational analysis (Figure 6E). We chose three of the five residues from the ZA loop region, namely, the hydrophobic amino acid residues 
I586 and F587, which are part of the RIF shelf similar to the WPF shelf in BET bromodomains, and Y599, which faces the acetyllysine binding pocket of the BRPF2 bromodomain. The remaining two residues, N642 and F648, were selected from the BC loop region. We mutated these residues to alanine, except two residues, I586 and Y599, which were mutated to phenylalanine. Using a bacterial expression system, we expressed all the five mutants and purified them with high homogeneity for the binding studies (Figure S4). We carried out pull-down assays by incubating the BRPF2 bromodomain mutants with the endogenous hyperacetylated histone H4. The bound proteins were enriched with Ni-NTA bead, followed by western blot with anti-H4K5ac antibody revealed that the Y599F and N642A mutants significantly abolishes the interaction with the histone H4K5ac mark (Figure 6F). We also observed that the F648A mutation reduced the binding approximately 1.5-fold, and F587A showed a minimal binding effect, whereas I586F enhanced the interaction with the H4K5ac mark (Figure 6F). These results closely support the ITC binding studies carried out for the BRPF2 bromodomain mutants F587A, Y599F, and N642A with the histone H4K5ac peptide ligand (Figure S5A-C).

Next, we performed circular dichroism (CD) experiments for the BRPF2 bromodomain mutants to verify whether the loss of binding is due to any conformational changes in the protein after the mutation. Analysis of the BRPF2 bromodomain wild-type and its mutants revealed no significant alterations in the bromodomain secondary structure (Figure 7A). We further characterized the melting temperature $\left(T_{\mathrm{m}}\right)$ of the BRPF2 bromodomain mutants by a thermal shift assay. We found that the Y599F and N642A mutants displayed significantly lower $T_{\mathrm{m}}$ than the wild-type protein (Figure 7B), which was very likely due to the destabilization of the overall fold of the bromodomain. In contrast, the F648A mutant showed a higher stabilization profile. Conversely, the other two mutants, I586F and F587A, showed similar $T_{\mathrm{m}}$ values as compared to 
the wild-type. Overall, these $T_{\mathrm{m}}$ values are in good agreement with the binding affinities of the mutants for H4K5ac marks in the ITC and pull-down experiments (Figure 6F, and Figure S5AC). Collectively, these results suggest that the ZA loop and BC loop of the BRPF2 bromodomain plays a vital role in stabilizing the overall fold of the bromodomain and acetyllysine recognition.

\section{BRPF2 Bromodomain Strongly Recognizes H4K5ac marks at the Mononucleosome Level.}

To address whether the BRPF2 bromodomain prefers to recognize identified histone H4 marks bearing the nucleosomes, we isolated mononucleosomes using MNase fragmented chromatin derived from HeLa nuclei (Figure 8A and Figure S6A,B). We then performed pull-down experiments on the mononucleosomal pools employing 6xHis-tagged BRPF2 bromodomain and subsequently enriched them with Ni-NTA beads, followed by western blot with anti-acetylated H4 antibodies. Notably, we found that the H4K5ac mark associates more robustly with the BRPF2 bromodomain as compared to H4K8ac, H4K12ac, and H4K16ac marks at the mononucleosomal level (Figure 8B). Furthermore, we also observed substantial enrichment of the H4K8ac marks by the BRPF2 bromodomain, and these observations are consistently supplemented by the pull-down assays conducted with the endogenous acetylated histone H4 (Figure 6B). We interpret the enhanced binding of $\mathrm{H} 4 \mathrm{~K} 5 \mathrm{ac}$ and $\mathrm{H} 4 \mathrm{~K} 8 \mathrm{ac}$ bearing-mononucleosomes to suggest that both marks may play a role in nucleosome-level binding, yet the H4K5ac interaction is dominant. We observed minimal binding of H4K12ac and H4K16ac marks to the BRPF2 bromodomain. Together, these results are closely supported by our ITC binding and pull-down assays carried out for the BRPF2 bromodomain with $\mathrm{H} 4$ peptides and endogenous histone H4, respectively (Figure 2B, Figure 3AC, and Figure 6B). 


\section{DISCUSSION}

The BRPF2 and BRPF3 scaffolding proteins are important for the HAT activity of HBO1, which acetylates histone $\mathrm{H} 3$ and H4. ${ }^{18,19}$ These scaffolding proteins regulate the HAT activity of HBO1 towards $\mathrm{H} 3 \mathrm{~K} 14$, and the deletion of $\mathrm{HBO} 1$ in mice exhibited a profound reduction of global H3K14 acetylation causing defects in embryonic development. ${ }^{19}$ Similarly, the loss of BRPF2 in mice led to a decreased histone H3 lysine 14 acetylation at the promoters of erythroid developmental regulator genes. ${ }^{21}$ However, it is not clear how BRPF2 directs the recruitment of HBO1 HAT to chromatin to regulate the gene transcription. Recent studies on the BRPF3 bromodomain demonstrate that it recognizes multiple acetylated lysine residues on the $\mathrm{N}$-terminal tails of histone $\mathrm{H} 4$ and shows preferential interactions with $\mathrm{H} 4 \mathrm{~K} 5 \mathrm{ac}$ and H4K5acK12ac marks. ${ }^{36}$ Since the sequence similarity between the BRPF2 and BRPF3 bromodomains is high, most likely, the BRPF2 bromodomain recognizes a similar set of acetylated histone modifications. As expected, we found that the BRPF2 bromodomain has a similar preference for selecting acetyllysine modifications on the histone H4 tail. Additionally, we found that the BRPF2 bromodomain strongly binds to H4K8ac and has a weak affinity for the H3K14ac ligands. Collectively, our ITC binding studies suggest that the BRPF2 and BRPF3 bromodomains have slightly different preferences for binding to the acetylated histone ligands due to the variability in the $\mathrm{ZA}$ and $\mathrm{BC}$ loop regions of the bromodomain.

Previous studies have reported that the BRPF2 bromodomain can recognize diacetylated histone H4K5acK8ac ligand with an affinity of $156 \pm 3.0 \mu \mathrm{M}$ as measured by ITC. ${ }^{37}$ Interestingly, I586F mutation in the "RIF shelf" region of the BRPF2 bromodomain did not impair acetyllysine binding. Moreover, it permitted the selection of butyrylated H4K5buK8bu ligand with a dissociation constant, $K_{\mathrm{D}}=130 \pm 10 \mu \mathrm{M} \cdot{ }^{37}$ These results are consistent with our pull-down 
experiments performed with endogenous acetylated histone $\mathrm{H} 4$, revealing that the BRPF2-I586F mutant has enhanced binding with the H4K5ac modification compared to the wild-type protein.

Flexible ligand docking followed by MD simulation studies were used to model the BRPF2 bromodomain and histone H4 peptide complexes. Our MD models suggest that hydrophobic interactions between the residues (I586, F587, V591, and F648) of the bromodomain and histone peptides drive acetyllysine binding. Once inserted into the binding cavity, acetyllysine makes strong hydrogen bonds with Y599 and N642 residues. These residues are part of the ZA and BC loop regions, are highly conserved throughout the bromodomain family, and play a critical role in acetyllysine recognition. ${ }^{10,11}$

Analysis of the BRPF2 mutants coupled with pull-down and ITC binding assays identified the critical residues involved in the acetyllysine binding. Notably, the Y599F and N642A mutations completely abolished the binding interaction between the BRPF2 bromodomain and the H4K5ac ligand, due to the loss of water coordination and direct hydrogen bonding with acetyllysine residue in Y599F and N642A mutants, respectively. Thus, the ordered water molecules in the bromodomain binding pocket and conserved asparagine "anchor" residue is critical for recognizing acetylated histone ligands. ${ }^{48,} 49$ Recent studies have extensively characterized the histones targets of the family IV bromodomains, including BRPF1, BRPF3, ATAD2, and ATAD2B bromodomains. These proteins have a preference for selecting the histone H4K5ac and H4K5acK12ac ligands with varying binding affinities. ${ }^{35,36,47,50}$ Importantly, our study shows that the BRPF2 bromodomain has a similar preference for selecting the histone H4K5ac and H4K5acK12ac ligands with a higher affinity and a moderate affinity to tetraacetylated H4Kac4 (H4K5/8/12/16) ligand. 
Although many studies focus on individual histone PTMs in isolation, recent studies have shown that the BPTF bromodomain strongly discriminates between acetylated histone H4 marks at the peptide versus nucleosome level. ${ }^{42} \mathrm{We}$ also characterized the interactions between the BRPF2 bromodomain and histone H4 marks at the nucleosome level. We found that the BRPF2 bromodomain bound a greater quantity of H4K5ac mononucleosomes as compared to the other histone H4 modifications. Overall, our nucleosomal enrichment data demonstrate that the H4K5ac mark is the preferred histone target of the BRPF2 bromodomain.

\section{CONCLUSION}

This study discovered novel histone ligands of the BRPF2 bromodomain that specifically recognizes different acetyllysine marks on the $\mathrm{N}$-terminal tails of histone $\mathrm{H} 4, \mathrm{H} 3$, and $\mathrm{H} 2 \mathrm{~A}$. We identified that the mono-(H4K5ac, H4K8ac) and di- (H4K5acK12ac) acetylated histone peptides are the preferred targets of the BRPF2 bromodomain. We establish that the BRPF2 bromodomain strongly binds to H4K5ac marks on histone peptides, endogenous histones, and mononucleosomal levels. Notably, it has been shown that the BRPF2-HBO1 co-localizes in the genome and shares a significant portion of their target genes involved in transcriptional regulation. Additionally, BRPF2-HBO1 interaction is critical for the proper functioning of $\mathrm{HBO} 1$, particularly in the global acetylation of H3K14. Thus, our findings offer a potential molecular mechanism that the BRPF2 bromodomain recruits the HBO1 HAT to chromatin by recognizing its histone interacting partners for the downstream transcriptional regulation. 


\section{ACCESSION CODES}

BRPF2 (BRD1): O95696 (UniProt ID)

\section{ASSOCIATED CONTENT}

\section{Supporting Information}

The Supporting Information is available free of charge on the ACS Publications website at DOI:

The Supporting Information contain peptide characterization including ESI-MS peptide data, HPLC purity traces for peptides, ITC binding data, Figure S1-S28 and Table S1-S3.

\section{AUTHOR INFORMATION}

\section{Corresponding Author}

*E-mail: s.babu@iiserkol.ac.in

\section{ORCID}

Babu Sudhamalla: 0000-0002-6610-1424.

\section{AUTHOR CONTRIBUTIONS}

B.S. conceived the ideas. S.B., A.R., and B.S. designed the experiments. S.B., A.R., and J.P. performed the biochemical experiments. S.B. carried out the docking and MD simulations studies. S.B., AR., J.P., and B.S. analyzed data. B.S. wrote the paper.

\section{Funding}

This work was supported by grants from SERB (SRG/2019/000765, EEQ/2020/000149) and DBT Ramalingaswami Fellowship (BT/RLF/Re-entry/56/2018) to B.S.

\section{Notes}

The authors declare no competing financial interest. 


\section{ACKNOWLEDGMENTS}

The authors thank the research funding from IISER Kolkata, infrastructural facilities supported by IISER Kolkata, and DST-FIST (SR/FST/LS-II/2017/93).

\section{ABBREVIATIONS}

BRD: Bromodomain; ITC: Isothermal titration calorimetry; MD: Molecular dynamics; BRPF1/2/3: Bromodomain and PHD finger containing protein 1/2/3; PHD: Plant homeodomain; ATAD2B: ATPase family AAA+ domain containing 2B; PTM: Posttranslational modifications; HBO1: Histone acetyltransferase binding to ORC1; RMSD: Root-mean-square deviation; TSA: Trichostatin A.

\section{Data availability statement}

All the relevant data are contained within this article and in the supporting information.

\section{REFERENCES}

[1] Rothbart, S. B., and Strahl, B. D. (2014) Interpreting the language of histone and DNA modifications, Biochim Biophys Acta 1839, 627-643.

[2] Bannister, A. J., and Kouzarides, T. (2011) Regulation of chromatin by histone modifications, Cell Res 21, 381-395.

[3] Wozniak, G. G., and Strahl, B. D. (2014) Hitting the 'mark': interpreting lysine methylation in the context of active transcription, Biochim Biophys Acta 1839, 1353-1361.

[4] Marmorstein, R., and Trievel, R. C. (2009) Histone modifying enzymes: structures, mechanisms, and specificities, Biochim Biophys Acta 1789, 58-68.

[5] Allfrey, V. G., Faulkner, R., and Mirsky, A. E. (1964) ACETYLATION AND METHYLATION OF HISTONES AND THEIR POSSIBLE ROLE IN THE REGULATION OF RNA SYNTHESIS, Proc Natl Acad Sci U S A 51, 786-794.

[6] Taverna, S. D., Li, H., Ruthenburg, A. J., Allis, C. D., and Patel, D. J. (2007) How chromatinbinding modules interpret histone modifications: lessons from professional pocket pickers, Nature Structural \& Molecular Biology 14, 1025-1040.

[7] Choudhary, C., Weinert, B. T., Nishida, Y., Verdin, E., and Mann, M. (2014) The growing landscape of lysine acetylation links metabolism and cell signalling, Nat Rev Mol Cell Biol $15,536-550$. 
[8] Park, J. M., Jo, S. H., Kim, M. Y., Kim, T. H., and Ahn, Y. H. (2015) Role of transcription factor acetylation in the regulation of metabolic homeostasis, Protein Cell 6, 804-813.

[9] Thiagarajan, D., Vedantham, S., Ananthakrishnan, R., Schmidt, A. M., and Ramasamy, R. (2016) Mechanisms of transcription factor acetylation and consequences in hearts, Biochimica et biophysica acta 1862, 2221-2231.

[10] Filippakopoulos, P., Picaud, S., Mangos, M., Keates, T., Lambert, J. P., Barsyte-Lovejoy, D., Felletar, I., Volkmer, R., Müller, S., Pawson, T., Gingras, A. C., Arrowsmith, C. H., and Knapp, S. (2012) Histone recognition and large-scale structural analysis of the human bromodomain family, Cell 149, 214-231.

[11] Filippakopoulos, P., and Knapp, S. (2012) The bromodomain interaction module, FEBS Lett 586, 2692-2704.

[12] Yang, X. J. (2015) MOZ and MORF acetyltransferases: Molecular interaction, animal development and human disease, Biochim Biophys Acta 1853, 1818-1826.

[13] Lloyd, J. T., and Glass, K. C. (2018) Biological function and histone recognition of family IV bromodomain-containing proteins, J Cell Physiol 233, 1877-1886.

[14] Ullah, M., Pelletier, N., Xiao, L., Zhao, S. P., Wang, K., Degerny, C., Tahmasebi, S., Cayrou, C., Doyon, Y., Goh, S. L., Champagne, N., Côté, J., and Yang, X. J. (2008) Molecular architecture of quartet MOZ/MORF histone acetyltransferase complexes, Mol Cell Biol 28, 6828-6843.

[15] Champagne, N., Pelletier, N., and Yang, X. J. (2001) The monocytic leukemia zinc finger protein MOZ is a histone acetyltransferase, Oncogene 20, 404-409.

[16] Holbert, M. A., Sikorski, T., Carten, J., Snowflack, D., Hodawadekar, S., and Marmorstein, R. (2007) The human monocytic leukemia zinc finger histone acetyltransferase domain contains DNA-binding activity implicated in chromatin targeting, J Biol Chem 282, 3660336613.

[17] Voss, A. K., Collin, C., Dixon, M. P., and Thomas, T. (2009) Moz and retinoic acid coordinately regulate $\mathrm{H} 3 \mathrm{~K} 9$ acetylation, Hox gene expression, and segment identity, Dev Cell 17, 674-686.

[18] Doyon, Y., Cayrou, C., Ullah, M., Landry, A. J., Côté, V., Selleck, W., Lane, W. S., Tan, S., Yang, X. J., and Côté, J. (2006) ING tumor suppressor proteins are critical regulators of chromatin acetylation required for genome expression and perpetuation, Mol Cell 21, 5164.

[19] Kueh, A. J., Dixon, M. P., Voss, A. K., and Thomas, T. (2011) HBO1 is required for H3K14 acetylation and normal transcriptional activity during embryonic development, $\mathrm{Mol}$ Cell Biol 31, 845-860.

[20] Lalonde, M. E., Avvakumov, N., Glass, K. C., Joncas, F. H., Saksouk, N., Holliday, M., Paquet, E., Yan, K., Tong, Q., Klein, B. J., Tan, S., Yang, X. J., Kutateladze, T. G., and Côté, J. (2013) Exchange of associated factors directs a switch in HBO1 acetyltransferase histone tail specificity, Genes Dev 27, 2009-2024.

[21] Mishima, Y., Miyagi, S., Saraya, A., Negishi, M., Endoh, M., Endo, T. A., Toyoda, T., Shinga, J., Katsumoto, T., Chiba, T., Yamaguchi, N., Kitabayashi, I., Koseki, H., and Iwama, A. (2011) The Hbo1-Brd1/Brpf2 complex is responsible for global acetylation of H3K14 and required for fetal liver erythropoiesis, Blood 118, 2443-2453.

[22] Tao, Y., Zhong, C., Zhu, J., Xu, S., and Ding, J. (2017) Structural and mechanistic insights into regulation of HBO1 histone acetyltransferase activity by BRPF2, Nucleic Acids Res $45,5707-5719$. 
[23] Feng, Y., Vlassis, A., Roques, C., Lalonde, M. E., González-Aguilera, C., Lambert, J. P., Lee, S. B., Zhao, X., Alabert, C., Johansen, J. V., Paquet, E., Yang, X. J., Gingras, A. C., Côté, J., and Groth, A. (2016) BRPF3-HBO1 regulates replication origin activation and histone H3K14 acetylation, Embo j 35, 176-192.

[24] Klein, B. J., Muthurajan, U. M., Lalonde, M. E., Gibson, M. D., Andrews, F. H., Hepler, M., Machida, S., Yan, K., Kurumizaka, H., Poirier, M. G., Côté, J., Luger, K., and Kutateladze, T. G. (2016) Bivalent interaction of the PZP domain of BRPF1 with the nucleosome impacts chromatin dynamics and acetylation, Nucleic Acids Res 44, 472-484.

[25] Laue, K., Daujat, S., Crump, J. G., Plaster, N., Roehl, H. H., Kimmel, C. B., Schneider, R., and Hammerschmidt, M. (2008) The multidomain protein Brpf1 binds histones and is required for Hox gene expression and segmental identity, Development 135, 1935-1946.

[26] Hibiya, K., Katsumoto, T., Kondo, T., Kitabayashi, I., and Kudo, A. (2009) Brpf1, a subunit of the MOZ histone acetyl transferase complex, maintains expression of anterior and posterior Hox genes for proper patterning of craniofacial and caudal skeletons, Developmental Biology 329, 176-190.

[27] Meier, J. C., Tallant, C., Fedorov, O., Witwicka, H., Hwang, S.-Y., van Stiphout, R. G., Lambert, J.-P., Rogers, C., Yapp, C., Gerstenberger, B. S., Fedele, V., Savitsky, P., Heidenreich, D., Daniels, D. L., Owen, D. R., Fish, P. V., Igoe, N. M., Bayle, E. D., Haendler, B., Oppermann, U. C. T., Buffa, F., Brennan, P. E., Müller, S., Gingras, A. C., Odgren, P. R., Birnbaum, M. J., and Knapp, S. (2017) Selective Targeting of Bromodomains of the Bromodomain-PHD Fingers Family Impairs Osteoclast Differentiation, ACS chemical biology 12, 2619-2630.

[28] Cheng, C. L.-H., Tsang, F. H.-C., Wei, L., Chen, M., Chin, D. W.-C., Shen, J., Law, C.-T., Lee, D., Wong, C. C.-L., Ng, I. O.-L., and Wong, C.-M. (2021) Bromodomain-containing protein BRPF1 is a therapeutic target for liver cancer, Communications Biology 4, 888.

[29] Meier, J. C., Tallant, C., Fedorov, O., Witwicka, H., Hwang, S. Y., van Stiphout, R. G., Lambert, J. P., Rogers, C., Yapp, C., Gerstenberger, B. S., Fedele, V., Savitsky, P., Heidenreich, D., Daniels, D. L., Owen, D. R., Fish, P. V., Igoe, N. M., Bayle, E. D., Haendler, B., Oppermann, U. C. T., Buffa, F., Brennan, P. E., Müller, S., Gingras, A. C., Odgren, P. R., Birnbaum, M. J., and Knapp, S. (2017) Selective Targeting of Bromodomains of the Bromodomain-PHD Fingers Family Impairs Osteoclast Differentiation, ACS Chem Biol 12, 2619-2630.

[30] Pérez-Salvia, M., and Esteller, M. (2017) Bromodomain inhibitors and cancer therapy: From structures to applications, Epigenetics 12, 323-339.

[31] Klein, B. J., Cox, K. L., Jang, S. M., Côté, J., Poirier, M. G., and Kutateladze, T. G. (2020) Molecular Basis for the PZP Domain of BRPF1 Association with Chromatin, Structure 28, 105-110.e103.

[32] Zhang, M., Lei, M., Qin, S., Dong, A., Yang, A., Li, Y., Loppnau, P., Hughes, T. R., Min, J., and Liu, Y. (2021) Crystal structure of the BRPF2 PWWP domain in complex with DNA reveals a different binding mode than the HDGF family of PWWP domains, Biochim Biophys Acta Gene Regul Mech 1864, 194688.

[33] Wu, H., Zeng, H., Lam, R., Tempel, W., Amaya, M. F., Xu, C., Dombrovski, L., Qiu, W., Wang, Y., and Min, J. (2011) Structural and histone binding ability characterizations of human PWWP domains, PLoS One 6, e18919. 
[34] Poplawski, A., Hu, K., Lee, W., Natesan, S., Peng, D., Carlson, S., Shi, X., Balaz, S., Markley, J. L., and Glass, K. C. (2014) Molecular insights into the recognition of N-terminal histone modifications by the BRPF1 bromodomain, J Mol Biol 426, 1661-1676.

[35] Obi, J. O., Lubula, M. Y., Cornilescu, G., Henrickson, A., McGuire, K., Evans, C. M., Phillips, M., Boyson, S. P., Demeler, B., Markley, J. L., and Glass, K. C. (2020) The BRPF1 bromodomain is a molecular reader of di-acetyllysine, Curr Res Struct Biol 2, 104-115.

[36] Barman, S., Roy, A., Bardhan, I., Kandasamy, T., Shivani, S., and Sudhamalla, B. (2021) Insights into the Molecular Mechanisms of Histone Code Recognition by the BRPF3 Bromodomain, Chem Asian J 16, 3404-3412.

[37] Flynn, E. M., Huang, O. W., Poy, F., Oppikofer, M., Bellon, S. F., Tang, Y., and Cochran, A. G. (2015) A Subset of Human Bromodomains Recognizes Butyryllysine and Crotonyllysine Histone Peptide Modifications, Structure 23, 1801-1814.

[38] Trott, O., and Olson, A. J. (2010) AutoDock Vina: improving the speed and accuracy of docking with a new scoring function, efficient optimization, and multithreading, J Comput Chem 31, 455-461.

[39] Berendsen, H. J. C., van der Spoel, D., and van Drunen, R. (1995) GROMACS: A messagepassing parallel molecular dynamics implementation, Computer Physics Communications 91, 43-56.

[40] Brooks, B. R., Brooks, C. L., 3rd, Mackerell, A. D., Jr., Nilsson, L., Petrella, R. J., Roux, B., Won, Y., Archontis, G., Bartels, C., Boresch, S., Caflisch, A., Caves, L., Cui, Q., Dinner, A. R., Feig, M., Fischer, S., Gao, J., Hodoscek, M., Im, W., Kuczera, K., Lazaridis, T., Ma, J., Ovchinnikov, V., Paci, E., Pastor, R. W., Post, C. B., Pu, J. Z., Schaefer, M., Tidor, B., Venable, R. M., Woodcock, H. L., Wu, X., Yang, W., York, D. M., and Karplus, M. (2009) CHARMM: the biomolecular simulation program, J Comput Chem 30, 1545-1614.

[41] Shechter, D., Dormann, H. L., Allis, C. D., and Hake, S. B. (2007) Extraction, purification and analysis of histones, Nat Protoc 2, 1445-1457.

[42] Ruthenburg, A. J., Li, H., Milne, T. A., Dewell, S., McGinty, R. K., Yuen, M., Ueberheide, B., Dou, Y., Muir, T. W., Patel, D. J., and Allis, C. D. (2011) Recognition of a mononucleosomal histone modification pattern by BPTF via multivalent interactions, Cell $145,692-706$.

[43] Khan, K. A., Ng, M. K., and Cheung, P. (2020) The Use of Mononucleosome Immunoprecipitation for Analysis of Combinatorial Histone Post-translational Modifications and Purification of Nucleosome-Interacting Proteins, Frontiers in Cell and Developmental Biology 8.

[44] Brand, M., Rampalli, S., Chaturvedi, C. P., and Dilworth, F. J. (2008) Analysis of epigenetic modifications of chromatin at specific gene loci by native chromatin immunoprecipitation of nucleosomes isolated using hydroxyapatite chromatography, Nat Protoc 3, 398-409.

[45] Louis-Jeune, C., Andrade-Navarro, M. A., and Perez-Iratxeta, C. (2012) Prediction of protein secondary structure from circular dichroism using theoretically derived spectra, Proteins 80, 374-381.

[46] Evans, C. M., Phillips, M., Malone, K. L., Tonelli, M., Cornilescu, G., Cornilescu, C., Holton, S. J., Gorjánácz, M., Wang, L., Carlson, S., Gay, J. C., Nix, J. C., Demeler, B., Markley, J. L., and Glass, K. C. (2021) Coordination of Di-Acetylated Histone Ligands by the ATAD2 Bromodomain, Int J Mol Sci 22.

[47] Lloyd, J. T., McLaughlin, K., Lubula, M. Y., Gay, J. C., Dest, A., Gao, C., Phillips, M., Tonelli, M., Cornilescu, G., Marunde, M. R., Evans, C. M., Boyson, S. P., Carlson, S., 
Keogh, M. C., Markley, J. L., Frietze, S., and Glass, K. C. (2020) Structural Insights into the Recognition of Mono- and Diacetylated Histones by the ATAD2B Bromodomain, $J$ Med Chem 63, 12799-12813.

[48] Vollmuth, F., Blankenfeldt, W., and Geyer, M. (2009) Structures of the dual bromodomains of the P-TEFb-activating protein Brd4 at atomic resolution, J Biol Chem 284, 3654736556.

[49] Crawford, T. D., Tsui, V., Flynn, E. M., Wang, S., Taylor, A. M., Côté, A., Audia, J. E., Beresini, M. H., Burdick, D. J., Cummings, R., Dakin, L. A., Duplessis, M., Good, A. C., Hewitt, M. C., Huang, H.-R., Jayaram, H., Kiefer, J. R., Jiang, Y., Murray, J., Nasveschuk, C. G., Pardo, E., Poy, F., Romero, F. A., Tang, Y., Wang, J., Xu, Z., Zawadzke, L. E., Zhu, X., Albrecht, B. K., Magnuson, S. R., Bellon, S., and Cochran, A. G. (2016) Diving into the Water: Inducible Binding Conformations for BRD4, TAF1(2), BRD9, and CECR2 Bromodomains, Journal of Medicinal Chemistry 59, 5391-5402.

[50] Evans, C. M., Phillips, M., Malone, K. L., Tonelli, M., Cornilescu, G., Cornilescu, C., Holton, S. J., Gorjánácz, M., Wang, L., Carlson, S., Gay, J. C., Nix, J. C., Demeler, B., Markley, J. L., and Glass, K. C. (2021) Coordination of Di-Acetylated Histone Ligands by the ATAD2 Bromodomain, International journal of molecular sciences 22, 9128. 


\section{Figure Legends}

Figure 1. The BRPF2 bromodomain and histone ligands were characterized in this study. (A) Domain organization of the BRPF2 contains two plant homeodomain (PHD) fingers, one bromodomain (BRD), and one proline-tryptophan-tryptophan-proline (PWWP) domain. (B) BRPF2 forms a complex with HBO1 HAT and two other proteins. (C) Cartoon representation showing the crystal structure of the BRPF2 bromodomain (PDB: 3RCW). The seconday structure elements are labeled. (D) Histone H4, H3, and H2A peptide sequences and the highlighted lysine residues were subjected to acetylation.

Figure 2. The BRPF2 bromodomain preferentially binds to mono-, and diacetylated histone H4. (A) Structural superimposition of BRPF2 bromodomain with histone H4K5ac and H4K5acK12ac peptide complexes are characterized by molecular docking study. The binding mode is similar for both the ligands, and the K5ac mark occupied the acetyl lysine binding pocket of the bromodomain. (B) Two representative ITC traces of H4K5ac and H4K5acK12ac ligands bind to the BRPF2 bromodomain. The BRPF2 bromodomain preferentially binds to the histone H4K5ac (1-10) and H4K5acK12ac (1-15) peptides with similar affinities with a $K_{\mathrm{D}}$ value of $1.4 \pm 0.02 \mu \mathrm{M}$ and $1.2 \pm 0.01 \mu \mathrm{M})$, respectively. Peptide sequences are shown in the inset.

Figure 3. Exothermic ITC plots for binding of the BRPF2 bromodomain with different acetylated histone peptides. (A) H4K8ac (1-15), (B) H4K12ac (1-20), (C) H4K16ac (11-21), (D) H4Kac4 (H4K5/8/12/16) (1-20), (E) H3K14ac (9-19), (F) H2AK5ac (1-12). The calculated binding constants are indicated. 
Figure 4. Stability of the BRPF2 bromodomain and histone H4 peptide complexes. (A) C $\alpha$ RMSD demonstrates the stability of the protein backbone during the MD simulation. (B) The Ca carbon RMSF of the BRPF2 bromodomain is plotted against the residue numbers. The BRPF2-histone H4K5ac and H4K5acK12ac peptide complexes are showed very similar fluctuations, but the BRPF2-unacetylated H4 peptide display observable changes in the ZA-loop region.

Figure 5. MD models showing the dynamics of acetyllysine binding in the bromodomain binding pocket. (A,B) Molecular surface representation of MD models showing the histone peptides H4K5ac and H4K5acK12ac bound to Kac-binding pocket of the BRPF2 bromodomain. The protein surface has been colored according to its electrostatic properties. (C,D) Cartoon representation shows the molecular contacts between the BRPF2 bromodomain and acetylated histone peptides H4K5ac and H4K5acK12ac. The solid and dotted lines represent the hydrogen bonding and hydrophobic interactions, respectively.

Figure 6. Interaction of BRPF2 bromodomain wild-type and its mutants with endogenous histone H4 (A) Hyperacetylated histone H4 was purified from HeLa cells. (B) The BRPF2 bromodomain was incubated with hyperacetylated H4 and bound acetylated H4 was enriched by Ni-NTA bead, followed by western blot against anti-acetylated H4 antibodies. (C) The BRPF2 bromodomain was incubated with hyperacetylated H4 in the presence or absence of BAY-299 inhibitor, and bound acetylated H4 was enriched by Ni-NTA bead, followed by western blot against anti-H4K5ac antibody. (D) The cartoon representation shows that the docked conformation of BAY-299 forms a hydrogen bond with N642 residue of the BRPF2 bromodomain. (E) The transparent cartoonsurface representation of the BRPF2 bromodomain shows the highlighted amino acid residues are subjected to mutagenesis. (F) The mutational analysis of acetyllysine binding pocket residues 
demonstrates that the Y599F and N642A mutants significantly abolished the interaction of BRPF2 bromodomain with H4K5ac modification as compared to the other mutants. The relative band intensities were measured by ImageJ and normalized for each immunoblotting. Bars represent mean \pm SD derived from $n=3$ individual experiments.

Figure 7. Circular dichroism spectra and thermal stability assay (TSA) of the wild-type and mutant BRPF2 bromodomains. (A) Secondary structure of the BRPF2 bromodomain wild-type and its mutants measured by circular dichroism. The percentage of $\alpha$-helical content for each bromodomain is listed in the inset. (B) Thermal stability assay shows the unfolding curve for the BRPF2 bromodomain wild-type and mutant proteins.

Figure 8. The BRPF2 bromodomain strongly recognizes the mono-acetylated H4K5ac mark at the mononucleosome level. (A) Schematic representation showing the isolation of mononucleosomes from HeLa cells. (B) Recombinantly produced 6xHis-tagged BRPF2 bromodomain was used to pull-down native mononucleosomes, and the bound material was probed by western blot against the anti-acetylated H4 antibodies. The relative band intensities were measured by ImageJ and normalized for each immunoblotting. Bars represent mean \pm SD derived from $n=3$ individual experiments.

Figure 9. Schematic model depicting the recruitment of BRPF2-HBO1 complex to chromatin for the downstream transcriptional regulation. 
Table 1. Dissociation constants of the interactions between BRPF2 bromodomain and acetylated histone peptides as measured by ITC.

\begin{tabular}{lll}
\hline Histone Peptide & Peptide Sequence & BRPF2 KD $(\boldsymbol{\mu M})$ \\
\hline H2A unmodified (1-12) & SGRGKQGGKARA & No binding \\
H2AK5ac (1-12) & SGRGKacQGGKARA & $165.2 \pm 15$ \\
H3 unmodified (1-24) & ARTKQTARKSTGGKAPRKQLATKA & No binding \\
H3K14ac (9-19) & KSTGGKacAPRKQ & $200.2 \pm 20$ \\
H4 unmodified (1-20) & SGRGKGGKGLGKGGAKRHRK & No binding \\
H4K5ac (1-10) & SGRGKacGGKGL & $1.4 \pm 0.02$ \\
H4K8ac (1-15) & SGRGKGGKacGLGKGGA & $5.2 \pm 0.7$ \\
H4K12ac (1-20) & SGRGKGGKGLGKacGGAKRHRK & $55.2 \pm 4.0$ \\
H4K16ac (11-21) & GKGGAKacRHRKVY & $160.5 \pm 15$ \\
H4K5acK12ac (1-15) & SGRGKacGGKGLGKacGGA & $1.2 \pm 0.01$ \\
H4Kac4 (K5/K8/K12/K16) (1-20) & SGRGKacGGKacGLGKacGGAKacRHRK & $20.5 \pm 2.0$ \\
\hline
\end{tabular}

Table 2. Summary of hydrogen bonds, and hydrophobic interactions between the strongest binding peptides and the BRPF2 bromodomain.

\begin{tabular}{|c|c|c|c|c|c|c|c|}
\hline \multicolumn{8}{|c|}{ Hydrogen Bonding } \\
\hline Peptide & Mark & Residue & $\begin{array}{l}\text { Distance } \\
\text { H-A }\end{array}$ & $\begin{array}{l}\text { Distance } \\
\text { D-A }\end{array}$ & $\begin{array}{l}\text { Donor } \\
\text { Angle }\end{array}$ & $\begin{array}{l}\text { Donor } \\
\text { Atom }\end{array}$ & $\begin{array}{l}\text { Acceptor } \\
\text { Atom }\end{array}$ \\
\hline \multirow[t]{3}{*}{ H4K5ac } & K5ac & R3 & 2.58 & 3.38 & 138.19 & 26 [N3] & 21 [O2] \\
\hline & & G6 & 2.18 & 2.6 & 104.1 & 38 [Nam] & 26 [N3] \\
\hline & & Y599 & 2.12 & 2.77 & 125.03 & 439 [O3] & $37[\mathrm{O} 2]$ \\
\hline \multirow[t]{4}{*}{ H4K5acK12ac } & K5ac & $\mathrm{R} 3$ & 2.26 & 3.11 & 144.69 & $26[\mathrm{~N} 3]$ & $21[\mathrm{O} 2]$ \\
\hline & & G7 & 2.99 & 3.47 & 111.18 & $42[\mathrm{Nam}]$ & $34[\mathrm{O} 2]$ \\
\hline & & Y599 & 2.34 & 3.11 & 139.75 & $439[\mathrm{O} 3]$ & $37[\mathrm{O} 2]$ \\
\hline & & N642 & 2.84 & 3.63 & 137.72 & $809[\mathrm{Nam}]$ & $37[\mathrm{O} 2]$ \\
\hline
\end{tabular}

\begin{tabular}{llll}
\hline \multicolumn{3}{c}{ Hydrophobic Interactions } \\
\hline Peptide & Mark & Residue & Distance \\
\hline H4K5ac & K5ac & I586 & 3.76 \\
& & F587 & 3.71 \\
H4K5acK12ac & F648 & 3.94 \\
& K5ac & I586 & 3.49 \\
& & V591 & 3.83 \\
& & F648 & 3.71 \\
\hline
\end{tabular}


Figure. 1

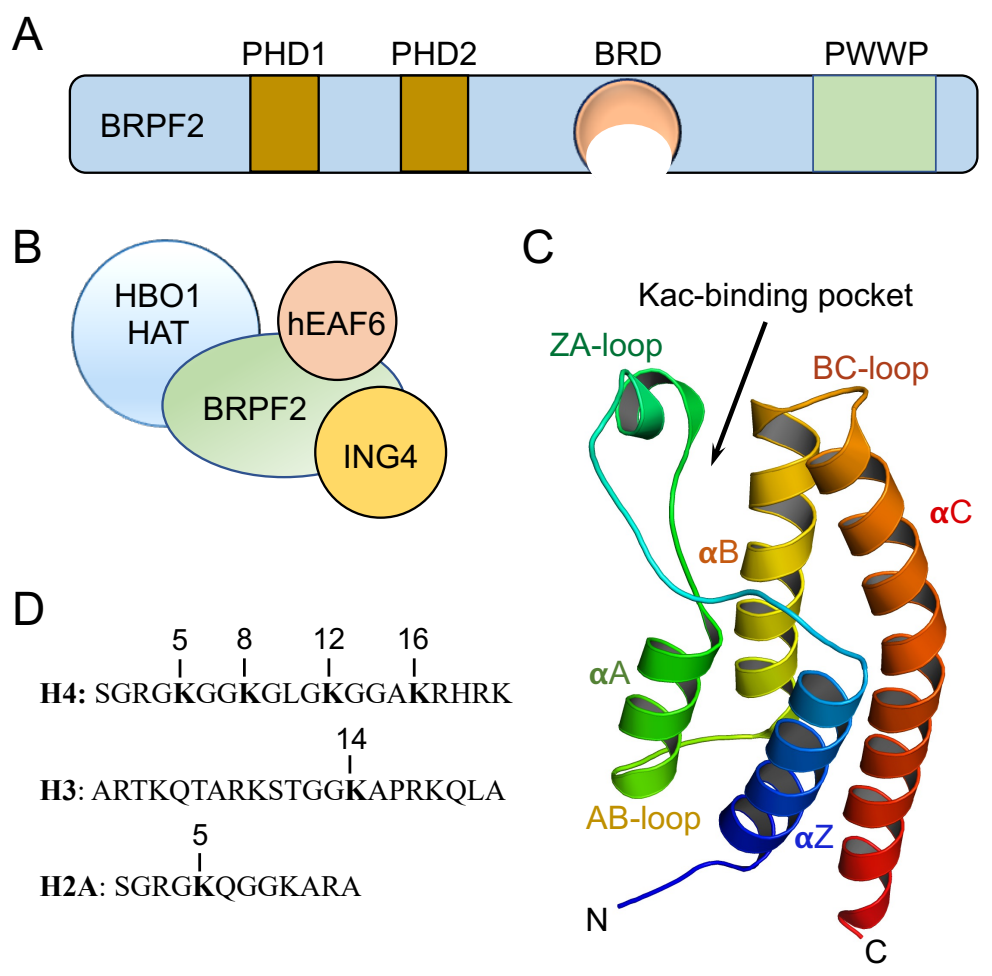


Figure. 2

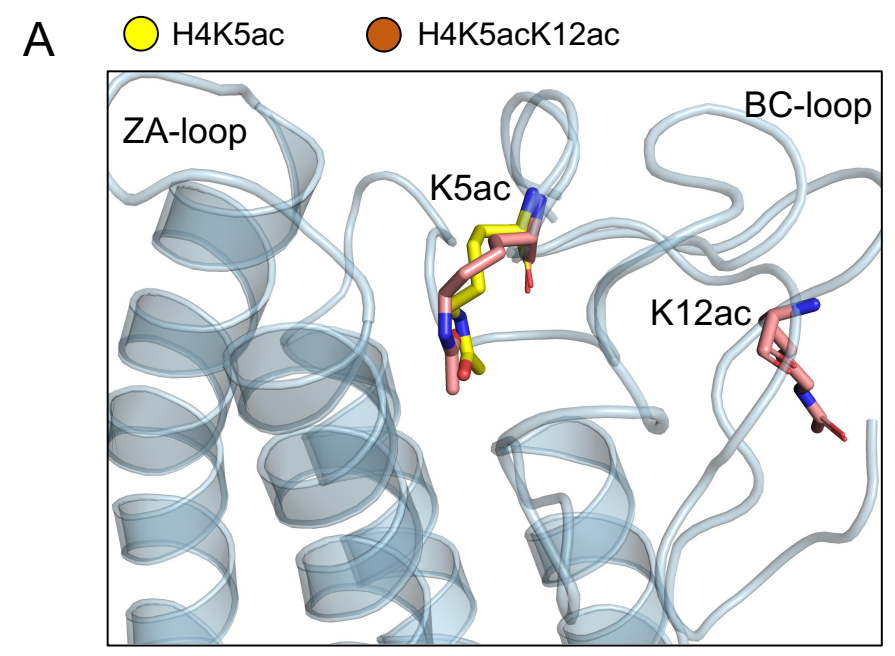

B

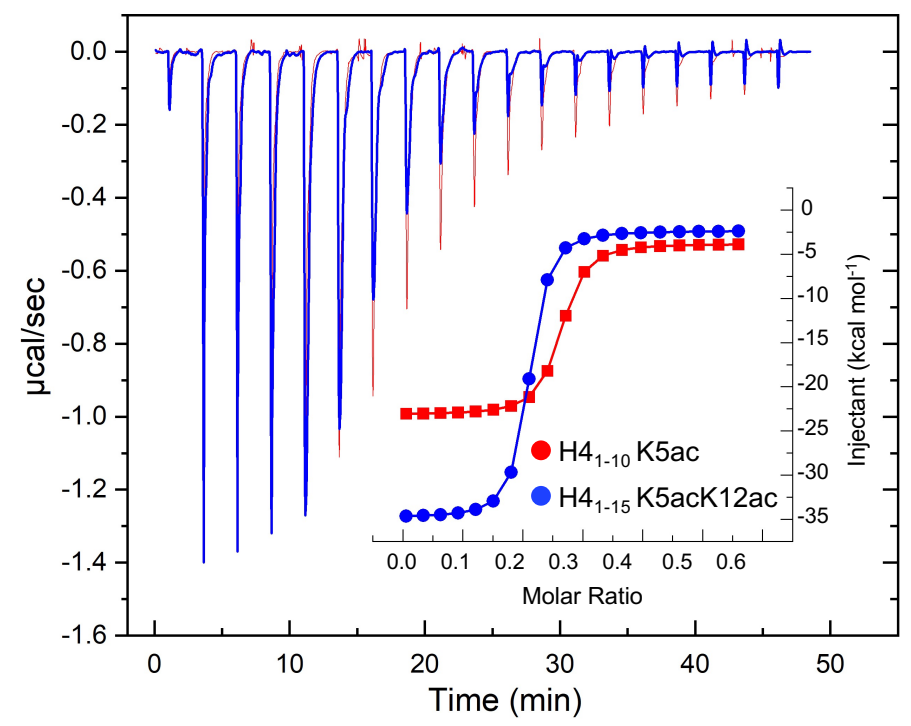


Figure. 3

A

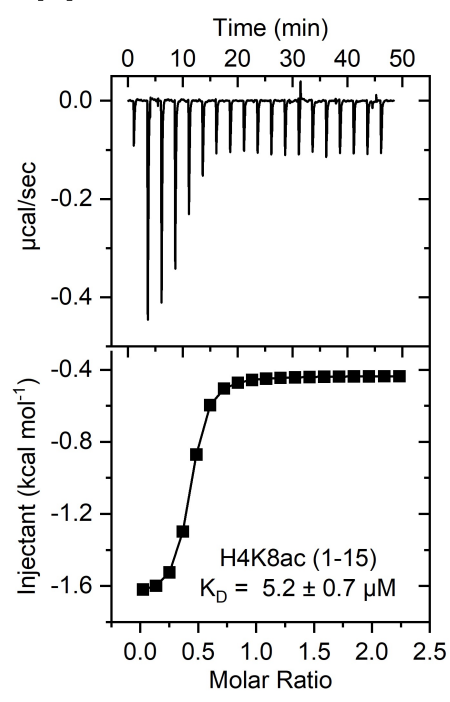

D

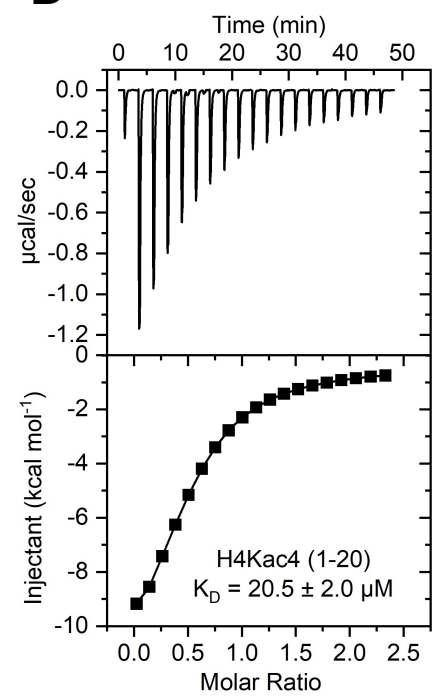

B

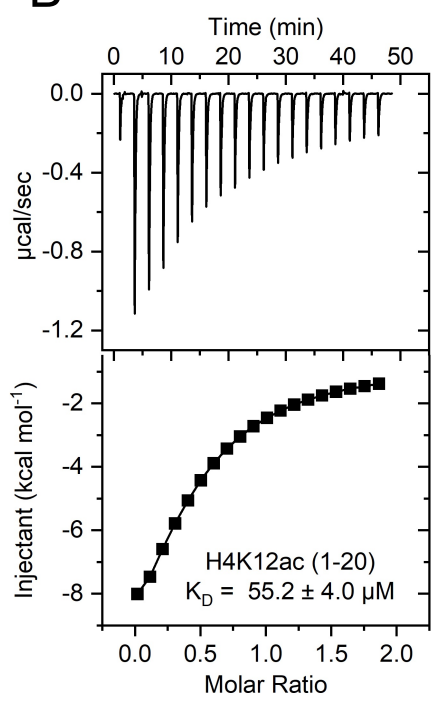

E

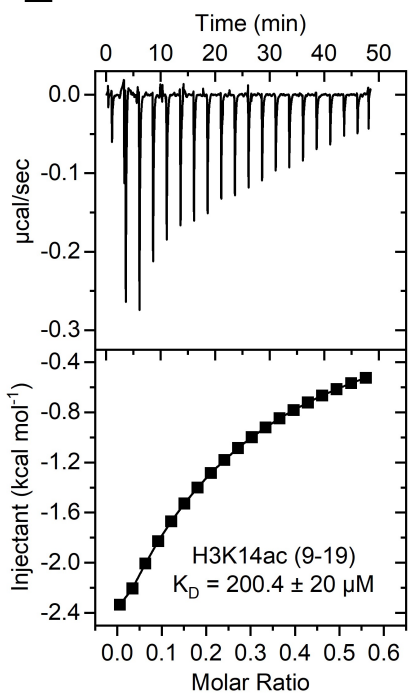

C

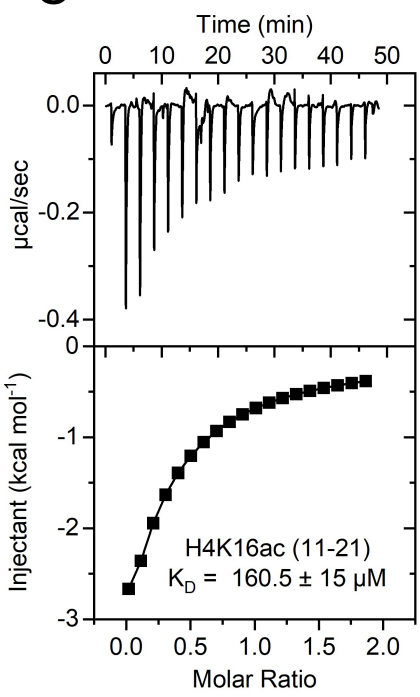

F

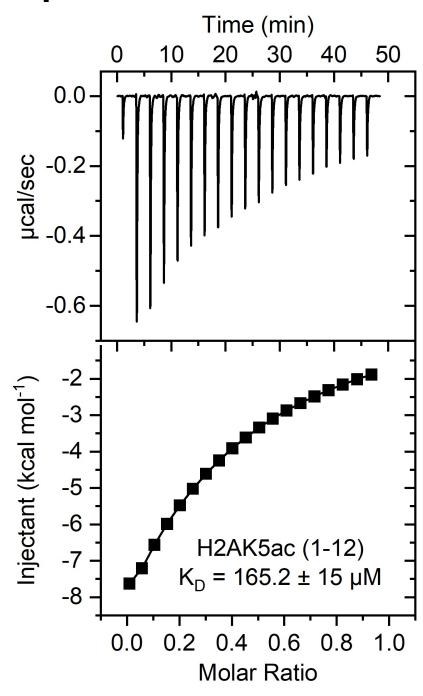


Figure. 4
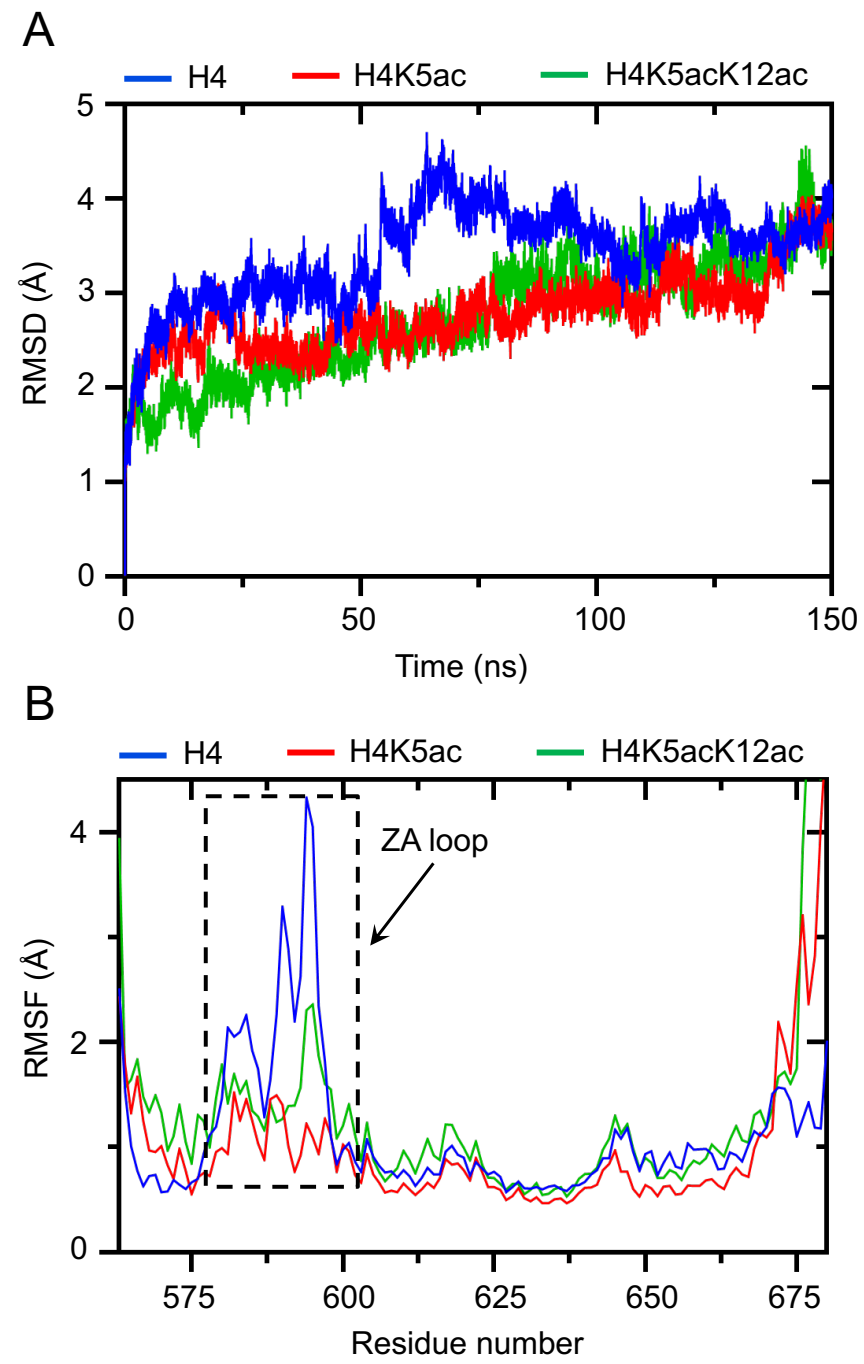
Figure. 5

A

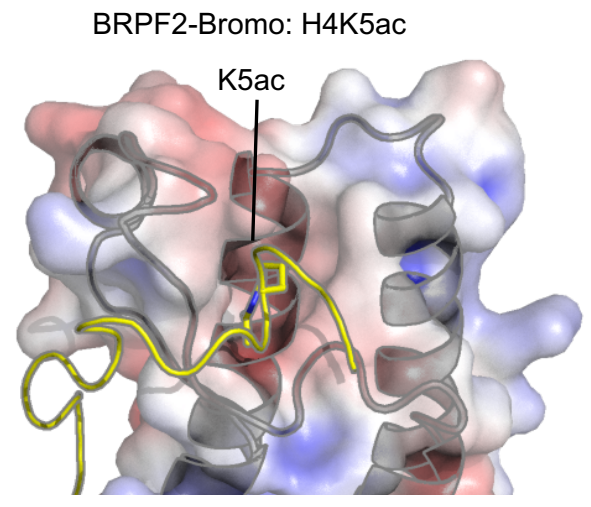

C

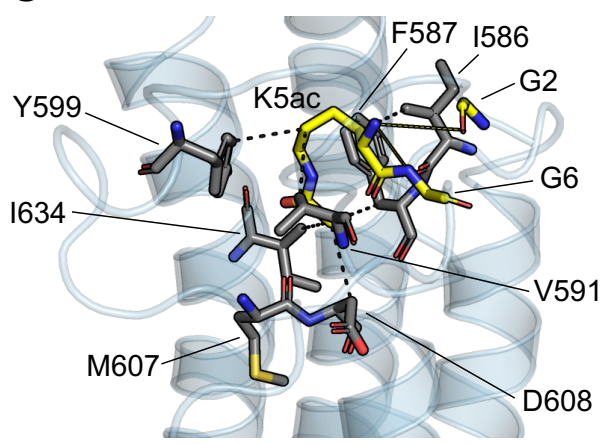

B

BRPF2-Bromo: H4K5acK12ac

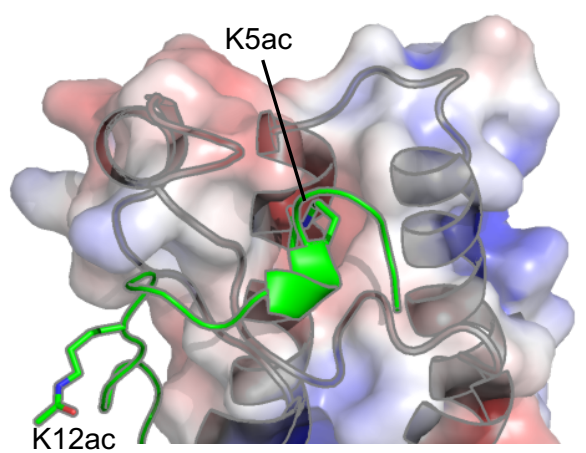

D

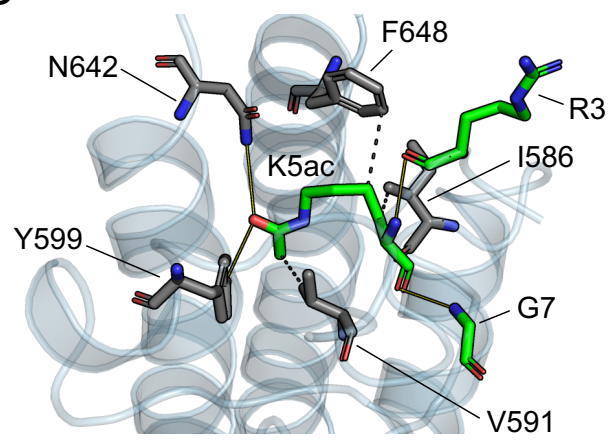


Figure. 6

A

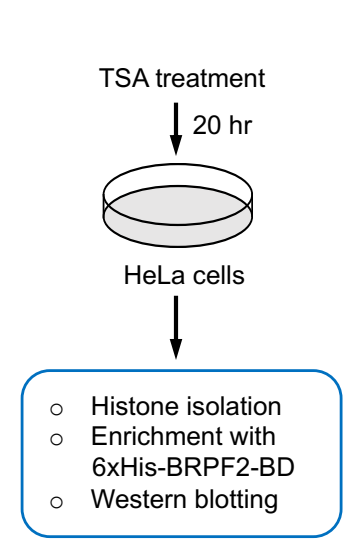

C

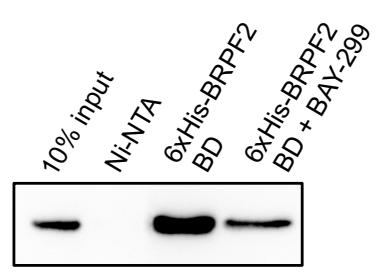

IB: $\alpha-H 4 K 5 a c$

E

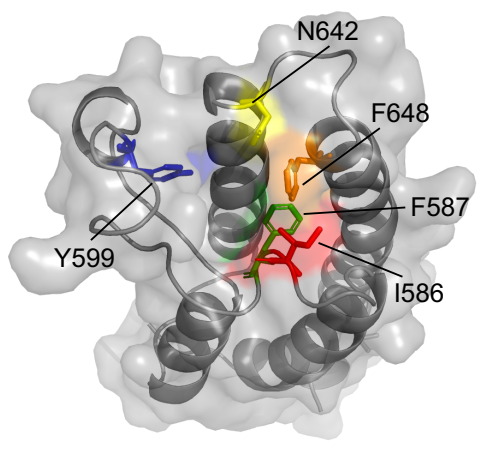

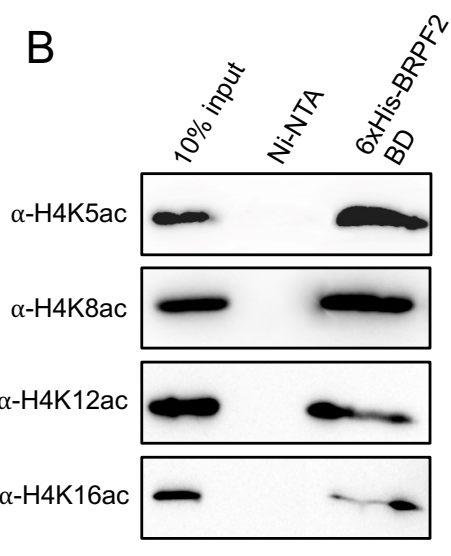

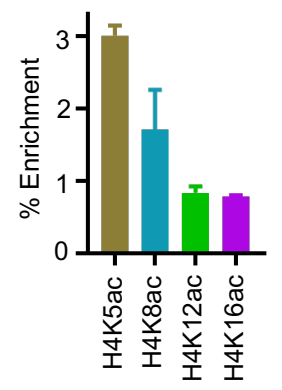

D
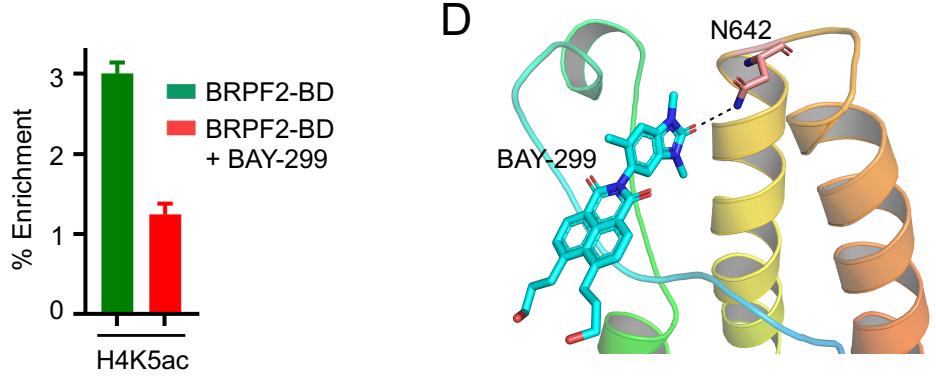

F
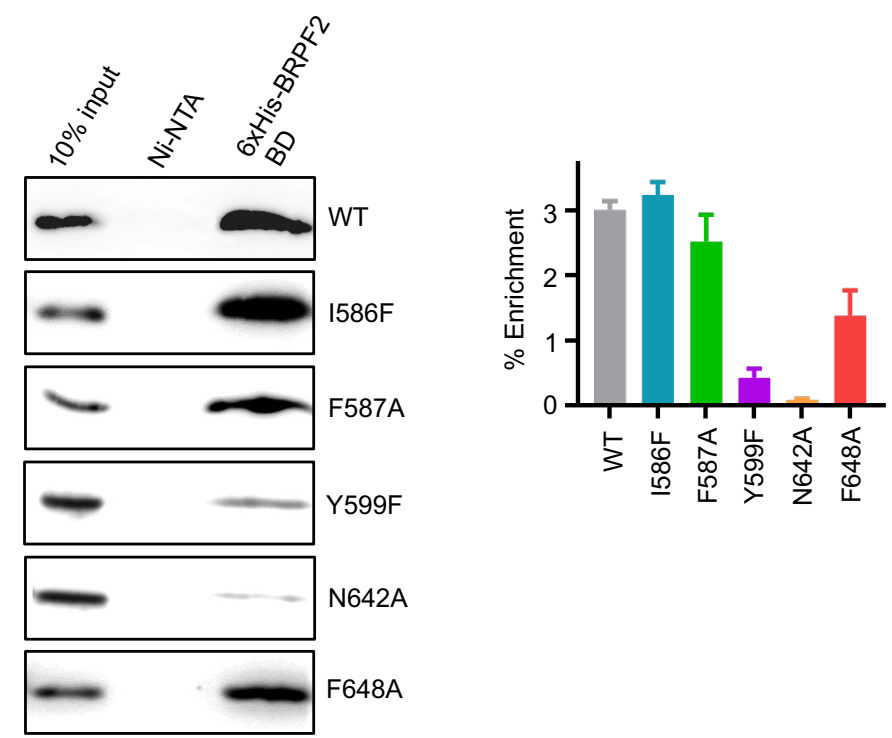

IB: $\alpha-H 4 K 5 a c$ 
Figure. 7

A

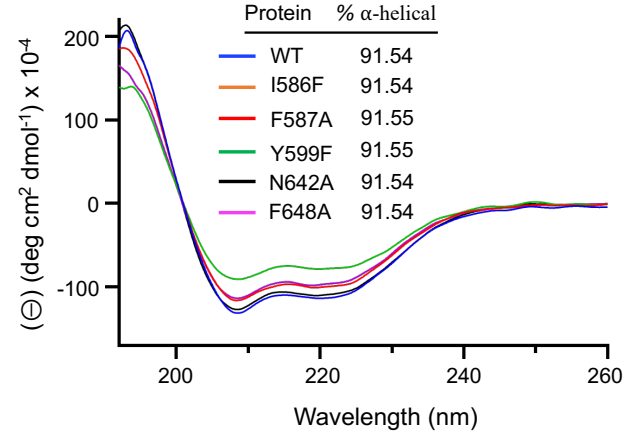

B

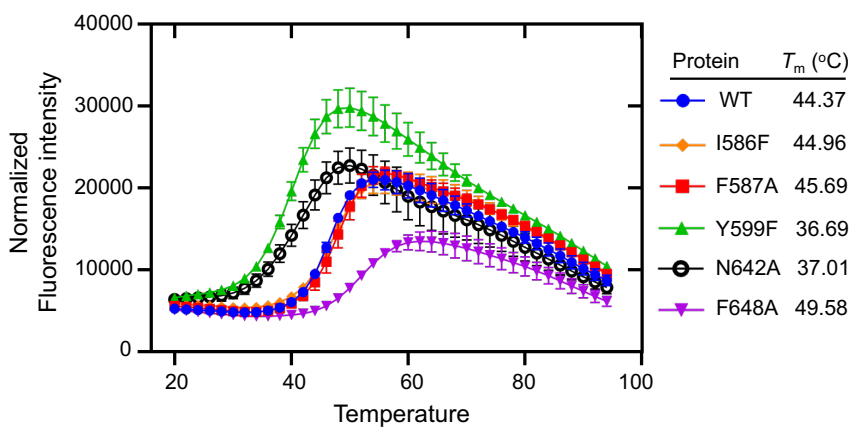


Figure. 8

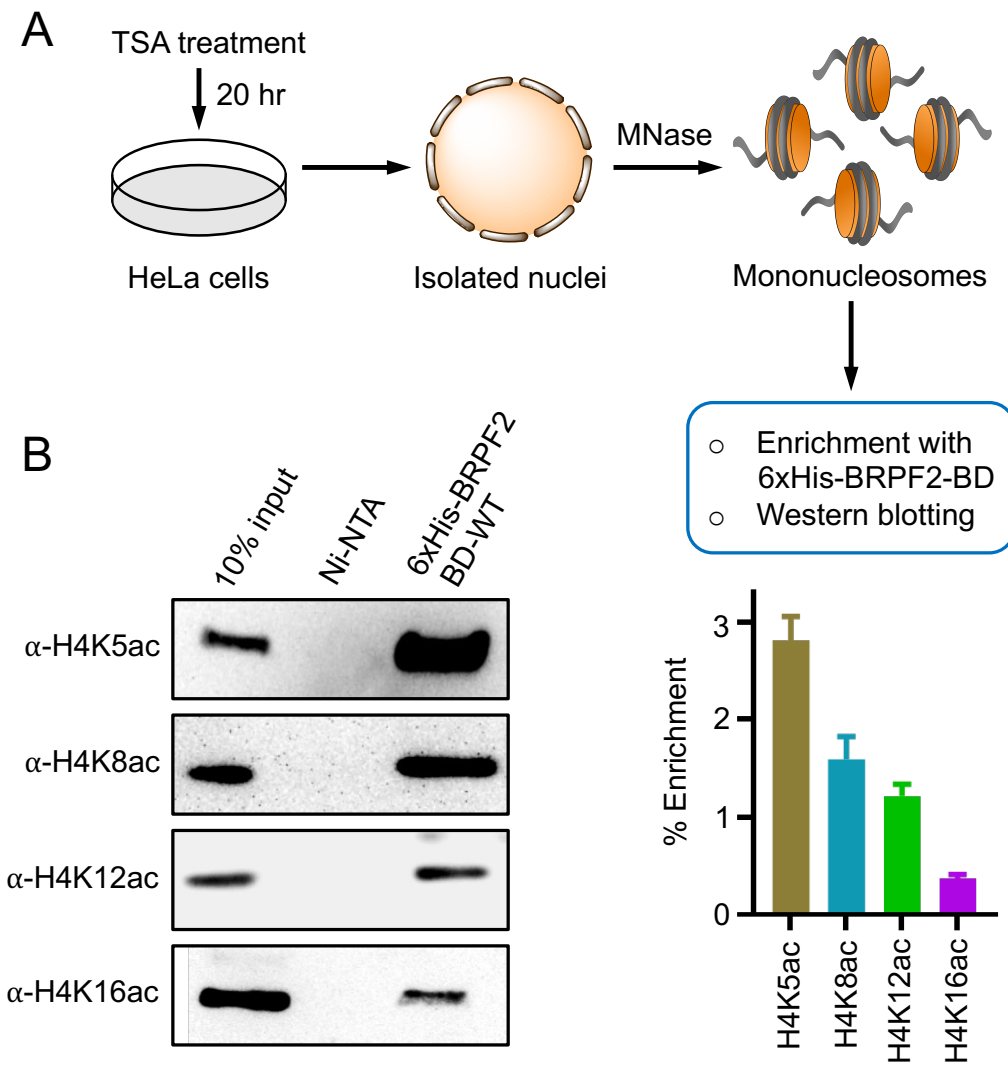


Figure. 9

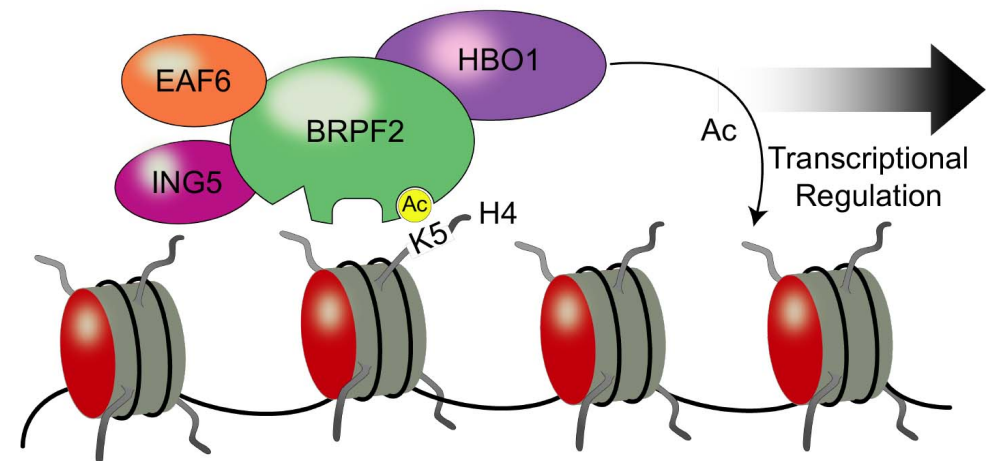


Table of Content Artwork

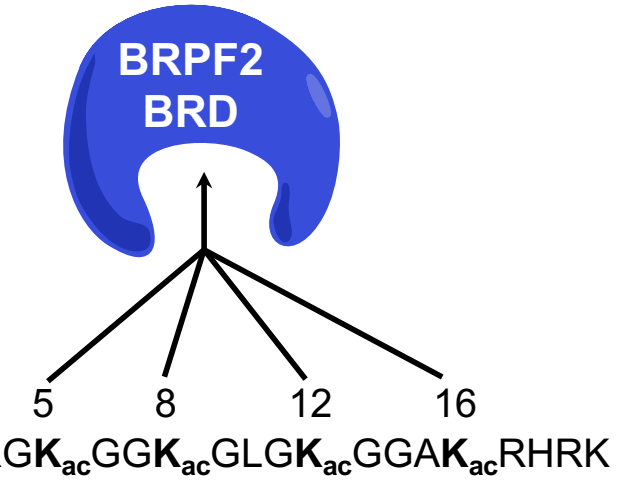

H4: SGRGK ${ }_{a c} G_{\text {G }}$ GLGK $_{a c} G_{\text {a }} K_{a c}$ RHRK 